\title{
HIGH FIELD MÖSSBAUER SPECTROSCOPY
}

\author{
J. CHAPPERT \\ DRF, Groupe Interactions Hyperfines \\ Centre d'Etudes Nucléaires de Grenoble, France
}

\begin{abstract}
Résumé. - Actuellement des champs magnétiques extérieurs variant entre quelques kOe et $150 \mathrm{kOe}$ sont couramment utilisés en spectroscopie Mössbauer. Dans cet article on passe en revue les possibilités offertes par l'adjonction à un spectromètre Mössbauer classique d'une bobine produisant un champ magnétique intense. Les principales caractéristiques d'expériences typiques ainsi que les récents développements de la spectroscopie Mössbauer sous champ intense sont discutés.
\end{abstract}

Abstract. - External magnetic fields ranging from a few kOe to $150 \mathrm{kOe}$ are now commonly used in Mössbauer Spectroscopy. In this paper the possibilities for solid state physics investigations which become possible when a coil producing a high external magnetic field is added to a conventional Mössbauer spectrometer are reviewed. Outlines of representative experiments as well as some recent technological developments of the high field Mössbauer spectrometry (HFMS) are discussed.

1. Introduction. - The first reported Mössbauer experiment in an external magnetic field was that of Hanna et al: [1] in 1960 who determined the sign of the hyperfine field in iron metal with the help of a conventional electromagnet giving a field of $20 \mathrm{kOe}$. Then in 1962 superconducting magnets $(35 \mathrm{kOe})$ were introduced in Mössbauer spectroscopy by Craig et al. [2] who confirmed the existence of giant magnetic moments in $\mathrm{PdFe}$. In early 1964, Blum et al. $[3,4]$ reported a comprehensive Mössbauer study of localized magnetic moments in metals using high field water cooled solenoids generating fields of up to $100 \mathrm{kOe}$. Apart from Heberle's paper at the 2nd Mössbauer Methodology Symposium in 1966 [5], no review paper has been devoted to the physical applications of Mössbauer spectroscopy in high magnetic fields. This may come from the fact that the high field Mössbauer spectroscopy (HFMS) has become so wide-spread and so many results have been reported that it seems almost impossible to review the entire domain. While such a view point may in fact be quite justified, it seems however appropriate to review and summarize in a unified fashion the new possibilities for solid state physics investigations which become possible when an intense magnetic field region becomes available in conjunction with normal Mössbauer experiments. It is with this aim in mind, that the present review has been conceived in the hope that the reader will be persuaded of the wealth of new information HFMS is capable of offering him. For the purposes of this summary, the paper has been divided (albeit somewhat arbitrarily) into six parts : paramagnetism — intramolecular magnetic ordering - magnetically ordered compounds - metals, alloys and intermetallic compounds - dilute alloys - experimental aspects. Each of these topics will be considered in turn in terms of the present development of the subject.

2. Paramagnetism. - 2.1 Spin hamiltonian. The Mössbauer effect has become a valuable tool for the investigation of magnetic ions in crystalline solids, since hyperfine interactions depend upon both the spin and orbital magnetism of the ion. The theory of hyperfine interactions in solids is based largely on the work of Abragam and Pryce [6] in EPR who introduced the so-called spin Hamiltonian $\mathfrak{H}_{\mathrm{SH}}$ [7]. This Hamiltonian can be used in the interpretation of Mössbauer spectra which reflect the existence of one or more magnetic hyperfine interactions between the nucleus and its surroundings. The concept of the spin Hamiltonian is based on the fact that if a group of energy levels is sufficiently well separated from all higher lying levels it can be isolated and treated independent of other energy states of the system. This group of levels will be characterized by a single quantum number $S$, even though each state is really a complicated mixture of the spin and orbital wave functions of the free ion. $S$ is called the effective or fictitious spin of the system and is defined by equating $2 S+1$ to the number of electronic levels in the lowest group. There is no need 
for $S$ to equal the free ion spin. As an example let us consider the $\mathrm{Fe}^{2+}$ ion (Fig. 1). In an octahedral cubic field the $3 \mathrm{~d}^{6}{ }^{5} \mathrm{D}$ term splits into a lower-orbital triplet and an upper-orbital doublet separated by

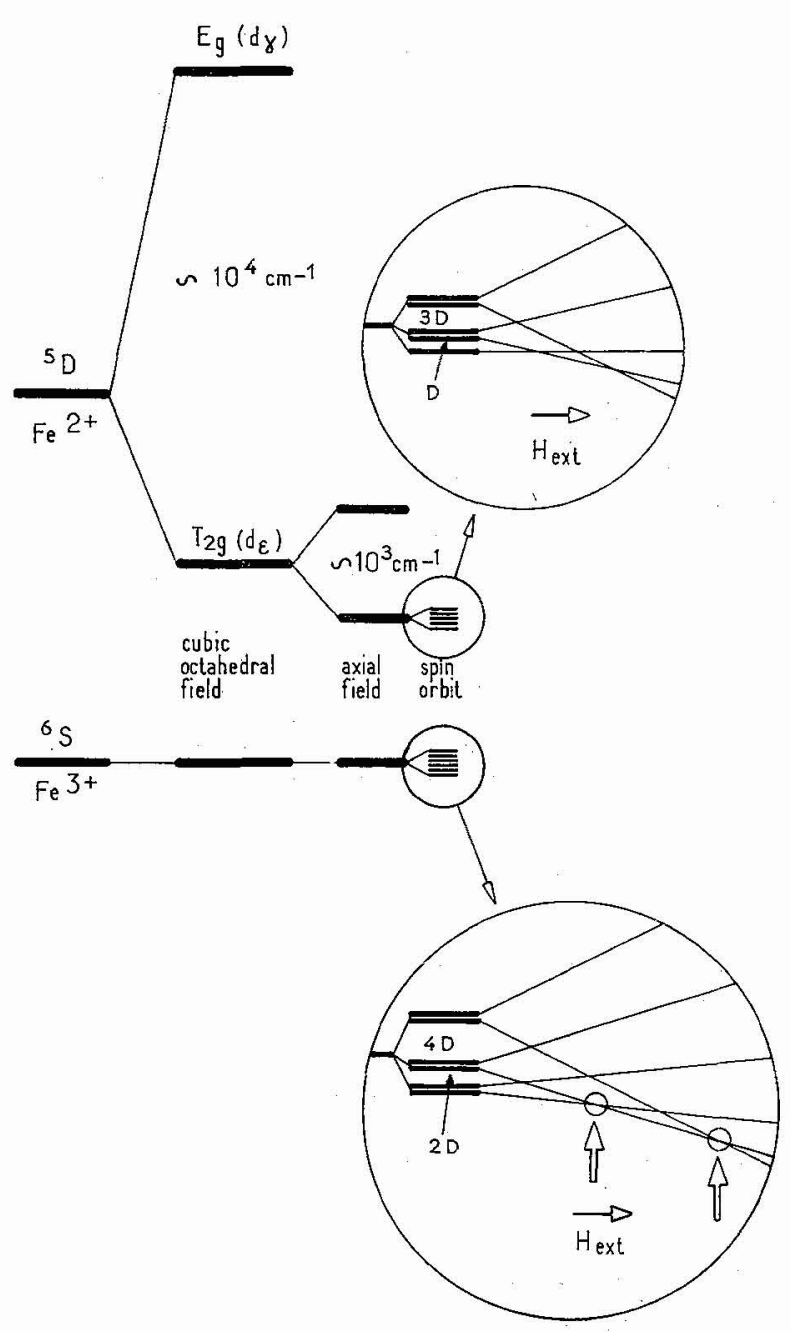

FIG. 1. - Energy level schemes of $\mathrm{Fe}^{2+}$ and $\mathrm{Fe}^{3+}$ ions subjected to cubic octahedral field, axial field $(D>0, E=0)$, spin orbit interaction and an axial external magnetic field. The circled inserts show details of the action of $H_{\text {ext. }} D$ is generally of the order of a few $\mathrm{cm}^{-1}$.

$10 \mathrm{Dq} \sim 10^{4} \mathrm{~cm}^{-1}$. An axial crystalline field further splits these groups by an amount $\Delta$. Then spin-orbit coupling partially removes the five-fold spin degeneracy, leaving a singlet and two Kramers doublets. Application of an external magnetic field, $H_{\text {ext }}$, splits the Kramers doublets by an amount $g \beta H_{\text {ext }}$, where $\beta$ is the Bohr magneton and $g$ is the $g$-factor. The energy level scheme represented in figure 1 applies for instance to ferrous fluosilicate [8] with $\Delta \sim 1000 \mathrm{~cm}^{-1}$. At temperature low compared with $\Delta$, the lowest level may be considered as isolated. Since the remaining degeneracy is 5 , the fictitious spin $(S=2)$ equals the free ion spin. Recent Mössbauer measurements indi- cate however that the $\mathrm{Fe}^{2+}$ site is not axial (G. Jehanno and F. Varret, this conference).

For most Mössbauer experiments it is sufficient to write the spin Hamiltonian in the following form,

$$
\begin{aligned}
\mathscr{H}_{\mathrm{SH}}=D\left[S_{z}^{2}-\right. & \left.\frac{1}{3} S(S+1)\right]+E\left(S_{x}^{2}-S_{y}^{2}\right)+ \\
& +\beta\left(\mathbf{H}_{\mathrm{ext}} \cdot \mathbf{g} \cdot \mathbf{S}\right) \\
& +\mathbf{I} \cdot \mathbf{A} \cdot \mathbf{S} \\
& +P\left[I_{z}^{2}-\frac{1}{3} I(I+1)\right]+\frac{\eta}{3}\left(I_{x}^{2}-I_{y}^{2}\right) \\
& -g_{\mathrm{n}} \beta_{\mathrm{n}} \mathbf{H}_{\mathrm{ext}} \cdot \mathbf{I}
\end{aligned}
$$

with the various interactions, listed in approximate order of decreasing energy: crystal-field, electronic Zeeman, magnetic and electric hyperfine, and nuclear Zeeman interactions. $I$ is the nuclear spin, $\beta_{\mathrm{n}}$ and $g_{\mathrm{n}}$ the nuclear Bohr magneton and $g$ factor respectively. The term in $D$ arises from axial crystal field while $E$ accounts for any rhombic distortion. The 4th line is the quadrupole interaction due to the electric field gradient (efg) at the nucleus which is not axial ( $\eta$ is the asymmetry parameter). $\mathbf{g}$ is the $\boldsymbol{g}$ tensor and $\mathbf{A}$ is the hyperfine tensor. Both tensors can be reduced to their three principal components $g_{x x}, g_{y y}, g_{z z} ; A_{x x}, A_{y y}, A_{z z}$. For axial symmetry it is sufficient to define

$$
\begin{aligned}
& g_{z z}=g_{\|} \\
& g_{x x}=g_{y y}=g_{\perp} \\
& A_{z z}=A_{\|} \\
& A_{x x}=A_{y y}=A_{\perp} .
\end{aligned}
$$

and

The S-state ions $\left(\mathrm{Fe}^{3+}\right)$ form a special case. Since the orbital angular momentum is zero, spin-orbit interaction can have no first order effect (Fig. 1). The charge distribution is spherically symmetrical and in first order the crystal field has no splitting effect on the six-fold spin degeneracy. In order to account for the observed splittings one has to calculate to higher orders of perturbation theory and the crystal field interaction (1st line of eq. (1)) may be written :

$$
\mathscr{H}_{\mathrm{CF}}=D\left(S_{z}^{2}-35 / 12\right)+\frac{a}{6}\left(S_{x}^{4}+S_{y}^{4}+S_{z}^{4}-\frac{707}{16}\right) .
$$

In $\mathrm{Al}_{2} \mathrm{O}_{3}: \mathrm{Fe}^{3+}$ the second term is approximately one order of magnitude smaller than the first one.

Having written a spin Hamiltonian containing a certain number of arbitrary parameters, one must now determine these parameters to fit the experimental data and interpret them in terms of the electronic and structural environment of the nucleus. 
2.2 Magnetic hyperfine INTERACTION. -2.2 .1$ Hyperfine field. - In eq. (1) the magnetic hyperfine interaction is represented by :

$$
\mathscr{H}_{\text {mhf }}=\mathbf{I} . \mathbf{A} \cdot \mathbf{S}-g_{n} \beta_{n} \mathbf{H}_{\text {ext }} \cdot \mathbf{I} .
$$

For large external magnetic fields $\left(g \beta H_{\text {ext }} \gg A\right)$ the spins are effectively quantized in the field direction and one may neglect off-diagonal terms. In that case the nucleus senses an effective field, $H_{\text {eff }}$, such that:

$$
\text { I.A. }\langle\mathbf{S}\rangle-g_{\mathrm{n}} \beta_{\mathrm{n}} \mathbf{H}_{\mathrm{ext}} . \mathbf{I}=-g_{\mathrm{n}} \beta_{\mathrm{n}} \mathbf{H}_{\mathrm{eff}} . \mathbf{I} \text {. }
$$

Therefore $H_{\text {eff }}$ is defined by :

$$
\mathbf{H}_{\text {eff }}=\mathbf{H}_{\text {ext }}-\frac{A<\mathbf{S}>}{g_{\mathrm{n}} \beta_{\mathrm{n}}}
$$

the electron spin enters eq. (6) as an expectation value because it is determined by $H_{\text {ext }}$ which tends to hold it fixed in magnitude and direction.

Defining

$$
\mathbf{H}_{\mathrm{hf}}=-\frac{A<\mathbf{S}\rangle}{g_{\mathrm{n}} \beta_{\mathrm{n}}},
$$

eq. (7) may be written :

$$
\begin{aligned}
\mathbf{H}_{\mathrm{eff}} & =\mathbf{H}_{\mathrm{ext}}+\mathbf{H}_{\mathrm{hf}} \\
& =\mathbf{H}_{\mathrm{ext}}+\frac{\langle\mathbf{S}\rangle}{S} H_{\mathrm{hf}}^{S}
\end{aligned}
$$

where $H_{\mathrm{hf}}^{S}=-A S / g_{\mathrm{n}} \beta_{\mathrm{n}}$ is the saturated value of the hyperfine field.

Analysis of the Mössbauer spectrum of a paramagnet subjected to $H_{\text {ext }}$ will provide the magnitude of $H_{\text {eff }}$ (at a given temperature) and its direction with respect to the principal axis of the efg. Because of anisotropy these parameters will depend on the direction of $H_{\text {ext }}$ and will therefore provide information on the anisotropy of the ion. The origin of the anisotropy of $H_{\mathrm{hf}}$ in $3 \mathrm{~d}$ elements has been extensively discussed by Marshall and Johnson [9-11]. The hyperfine field is made up of three contributions which are of two fundamental different kinds :

- A contact interaction due to the polarization of the core s-electrons by the magnetized $3 \mathrm{~d}$ electrons. This interaction is isotropic, so that for any direction of the magnetization it may be represented by an effective magnetic field at the nucleus which may be written

$$
H_{\mathrm{c}}=-2 \beta\left\langle r^{-3}\right\rangle k\langle S\rangle
$$

where $\left\langle r^{-3}\right\rangle$ is the $r^{-3}$ average for 3 d electrons and $k$ is a parameter which measures the polarization and which may be experimentally evaluated $[10,12]$.

- Non contact contribution, one from the orbital moment and one from the dipolar field of the electron spin. Both are anisotropic so they are tensor quantities. One must therefore always specify the direction $i$ of magnetization for which they are measured. The components of the orbital term are :

$$
\left.H_{\mathrm{Li}}=2 \beta<r^{-3}\right\rangle\left\langle L_{i}\right\rangle
$$

If the orbital momentum is almost completely quenched as in ferrous fluosilicate [8]

$$
L_{i}=\left(g_{i}-2\right) S_{i} .
$$

In cases of strong spin-orbit coupling, mixing of levels occurs and significant unquenching of orbital angular momentum results as in low spin Fe(III) complexes. Under these conditions eq. (13) is no longer valid [13].

The components of the dipolar field are :

$$
\begin{aligned}
H_{\mathrm{Di}}=2 \beta< & r^{-3}>(-3 \xi) \times \\
& \times\left(<L_{i}^{2}-\frac{1}{3} L(L+1)><S_{i}>\right. \\
& +\frac{1}{2}<L_{i} L_{j}+L_{j} L_{i}><S_{j}> \\
& \left.+\frac{1}{2}<L_{i} L_{k}+L_{k} L_{i}><S_{k}>\right)
\end{aligned}
$$

where $\xi$ depends upon the state of the ion $(-1 / 42$ for $\mathrm{Fe}^{2+}$ ). Summing these three contributions, the hyperfine field may be expressed as :

$$
H_{\mathrm{hf}, \mathrm{i}}=H_{\mathrm{c}}+H_{\mathbf{L i}}+H_{\mathrm{Di}} .
$$

In $\mathrm{Fe}^{2+}$ compounds these three contributions may be of the same order of magnitude ( 100-500 kOe); only the first one is present in $\mathrm{Fe}^{3+}$ ions. For most rare earth ions the dominant contribution (reaching several megaoersteds) is $H_{\mathrm{Li}}+H_{\mathrm{Di}}$ produced by the $4 \mathrm{f}$ electrons, while it is zero in $\mathrm{Gd}^{3+}$ and $\mathrm{Eu}^{2+}$ (S state ions).

2.2.2 Hyperfine field as a probe for structural studies. - An accurate knowledge of $H_{\mathrm{hf}}$ is a major piece of information in several respects, some of which we will now consider in detail. First of all application of an external magnetic field may not induce a hyperfine field. In that case $H_{\text {eff }}$ is identical to $H_{\text {ext }}$, which implies $S=0$, i. e. the ground electronic state is a singlet as in low spin ferrous compounds [12, 14-15]. However the lack of any observable $H_{\text {hf }}$ is not a unique characteristic of zero-spin systems. As we shall see below polynuclear clusters having antiferromagnetically coupled spins do not exhibit any $H_{\mathrm{hf}}$. When the ground state is not a singlet the magnitude of $H_{\text {hf }}^{S}$ allows a choice to be made between various possible electronic configurations [15-17]. Such an identification is undoubtedly more dependable than that deduced from isomer shift or quadrupole coupling measurements. Extensive use of this type of charge identification has been made in cases such as the haemoglobin compounds $[12,15,17]$, in ${ }^{57} \mathrm{Co}$ or $\mathrm{Fe}$ doped $\mathrm{MgO}[18,19], \mathrm{CaO}[20,21]$ and $\mathrm{KMgF}_{3}$ [22], in iron complexes with characteristic spin 0 or $\frac{1}{2}$ [23-24] as well as in europium hexammines [25]. As an exemple of the application of this technique may be cited the last of the above compounds, for which previous susceptibility measurements had indicated that the $\mathrm{Eu}$ ion might not be in a $4 f^{7}$ divalent configuration 
but in a $4 f^{9}$ or $4 f^{7} 5 d^{2}$ state at low temperatures. HFMS up to $70 \mathrm{kOe}$ strongly supports the $4 \mathrm{f}^{7}$ configuration [25].

Not only the magnitude of $H_{\mathrm{hf}}^{S}$ is of interest but also each of the three contributions (eq. (15)) which can be obtained from HFMS. First of all these contributions are very sensitive to covalency $[13,26]$ or the consequences of the Jahn-Teller effect [27]. Reduction factors are introduced in orbital and dipolar fields to correct for these effects which may also strongly reduce the core-polarization field per spin $H_{\mathrm{c}} / 2 S$ [28]. Correlation between covalency and field induced ${ }^{151} \mathrm{Eu}$ hyperfine fields observed in Eu-Ca hexammines has recently been reported by Parker and Kaplan [29]. A possible way to get an estimate of isotropic $H_{\mathrm{c}} / 2 \mathrm{~S}$ is to take advantage of the anisotropic character of the dipolar and orbital terms as demonstrated in uniaxial ferrous fluosilicate by Johnson [10], who measured $H_{\mathrm{hf}}$ on a single crystal with $H_{\text {ext }}$ applied along and perpendicular to the axis of symmetry and derived the anisotropy $H_{\mathrm{hf}}^{\mathrm{S}}(/ /)-H_{\mathrm{hf}}^{\mathrm{S}}(\perp)$, which is independent of $H_{\mathrm{c}}$. The parallel and perpendicular components of $H_{\mathbf{L}}$ and $H_{\mathrm{D}}$ were calculated using susceptibility data (eq. (13) is valid) and effective values of $\left\langle r^{-3}\right\rangle$ and $k$ were derived leading to (see eq. (11)) a core polarization field $H_{\mathrm{c}}=-422 \mathrm{kOe}$, i. e. $H_{\mathrm{c}} / 2 S=-105 \mathrm{kOe}$ per spin in agreement with free ion spin polarized Hartree-Fock calculations [26, $30]$ and with the so-called « $110 \mathrm{kOe}$ per spin » rule [31] (for ionic compounds).

An interesting consequence of anisotropy is the observation by König et al. [32] of a thermally induced high spin $\rightleftarrows$ low spin transition in an iron (II) complex. The magnetically perturbed Mössbauer spectrum above the transition temperature can only be accounted for by a highly anisotropic $H_{\mathrm{hf}}$ concentrated along the $z$-axis $\left(H_{\mathrm{hf}, z}=-23 \mathrm{kOe}, H_{\mathrm{hf}, x}=H_{\mathrm{hf}, y}=-2 \mathrm{kOe}\right)$.

It should be noted that single crystals are not needed for the determination of the components of the hyperfine tensor $[8,12,32]$. Working with polycrystalline samples one could expect broad lines since the external field direction is oriented at random angles with respect to the crystallographic symmetry axes. However at low $T$ lines are generally narrow $[8,33,34]$. This may be a consequence of the anisotropic susceptibility of the ions. In addition the effective field has a tendency to be directed at right angles to the symmetry axis since the probability that $H_{\text {ext }}$ will be oriented at an angle $\theta$ to the axis is proportional to $\sin \theta \mathrm{d} \theta$ which is maximum for $\theta=90^{\circ}$ [35]. For example Mössbauer spectra of polycrystalline ferrous fluosilicate [8, 34] in strong magnetic fields at $4.2 \mathrm{~K}$ show quite sharp lines similar to those for the single crystal with $H_{\text {ext }}$ perpendicular to the trigonal axis.

In the preceding discussion it was assumed that the temperature was maintained constant during the course of the experiment. Let us now consider the temperature as a variable and introduce a new parameter $\left(H_{\mathrm{ext}} / T\right)$. For an ideal paramagnet and assuming fast relaxation, it is well known that the $H_{\text {ext }} / T$ dependence of the hyperfine field is

$$
H_{\mathrm{hf}}=H_{\mathrm{hf}}^{S} B_{\mathrm{S}}\left(g \beta S H_{\mathrm{ext}} / k T\right)
$$

where $B_{S}\left(g \beta S H_{\text {ext }} / k T\right)$ is the Brillouin function for spin $S . H_{\mathrm{hf}}^{S}$ is determined from high $H_{\text {ext }} / T$ values and a fit of experimental data using eq. (16) allows the determination of $S$, as in iron [20,36-38] ytterbium [39] or europium [40] compounds. Figure 2 shows the fit obtained for two iron (I) compounds $[19,36]$. The problem with such a fit is the exact determination of $H_{\mathrm{hf}}^{\mathrm{S}}$. It may require very high values of $H_{\mathrm{ext}}$ to saturate $H_{\mathrm{hf}}$. One way to know that saturation has been reached is to change $T$ for the same $H_{\text {ext }}$. This should not change $H_{\mathrm{hf}}$. On the other hand very high external fields can produce mixing of the ground state with excited levels and change $H_{\mathrm{hf}}^{S}$ as observed in $\mathrm{MgO}: \mathrm{Fe}^{1+}$ [17] for $H_{\text {ext }}$ greater than $\sim 100 \mathrm{kOe}$ (curve $b$ of Fig. 2). However it should be emphasized that under these extreme conditions the fundamental assumptions on which the spin Hamiltonian was based are no longer valid and the ultimate interpretation of the experimental data becomes considerably more complex.

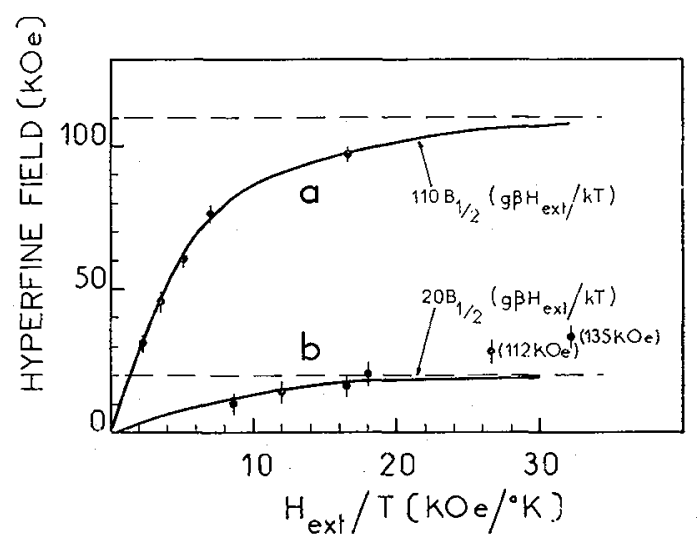

FIG. 2. - Dependence of $H_{\mathrm{hr}}$ on $H_{\mathrm{ext}} / T$ in two iron (I) complexes : (a) nitrosyliron bis(N, N-diethyldithiocarbamate) [36] ; (b) $\mathrm{MgO}: \mathrm{Fe}[17]$. Note in curve (b) the deviation from the Brillouin function (solid line) for $S=1 / 2$ at high values of $H_{\text {ext }}$.

2.3 CRYSTAL FIELD INTERACTION. - Up to now we have been interested only in the magnetic hyperfine interaction and have ignored the purely electronic part of the spin Hamiltonian (1st and 2nd lines of eq. (1)). The terms in $D$ and $E$ are responsible for the zero field splittings of the effective spin levels. When $H_{\text {ext }}$ is switched on, it acts as a perturbation and removes the spin degeneracy (see Fig. 1 for axial case). Depending upon values of $D, E$ and $g$, large fields may produce mixing of the ground state level with the excited states. For Kramers doublets (e. g. $\mathrm{Fe}^{3+}$ ), when $g \beta H_{\mathrm{ext}} \sim 2 D$ the two members of the ground state doublet have different values of $\langle S\rangle$. Mössbauer patterns are produced by each with an intensity weighted by the proper Boltzmann factor (they will be observed separately for slow relaxation [41]). Such 
high field spectra for slow and fast relaxation may be analyzed and estimates of $D$ and $E$ listed in Table I can be made. Oosterhuis and Lang [51] have tabulated the results of numerical calculations of the various spin Hamiltonian parameters for the $t_{2 \mathrm{~g}}^{4}$ electronic configuration. Of remarkable interest is the study of level crossing. Wickman and Wertheim [52] took advantage of the small values of $D\left(0.17 \mathrm{~cm}^{-1}\right)$ in $\mathrm{Al}_{2} \mathrm{O}_{3}: \mathrm{Fe}^{3+}$ to study in detail this behavior. They observed large changes in $H_{\mathrm{hf}}$ at the crossing points (see arrows in Fig. 1), and also the repulsion of levels due to the small cubic term of eq. (4).

\subsection{QUADRUPOLE INTERACTION. - 2.4.1 Parame-} ters of the quadrupole interaction. - The quadrupole interaction (4th line of eq. (1)) results from a non-zero efg at the nucleus. In the absence of a magnetic interaction the observed quadrupole splitting is proportional to $V_{z z}\left(1+\frac{\eta^{2}}{3}\right)^{1 / 2}$, where $V_{z z}$ is the principal component of the efg tensor and $\eta$ the asymmetry parameter defined by $\eta=\left(V_{x x}-V_{y y}\right) / V_{z z}$ so that

$$
\left|V_{z z}\right| \geqslant\left|V_{y y}\right| \geqslant\left|V_{x x}\right| \text {. }
$$

A knowledge of $V_{z z}$ (magnitude and sign) and $\eta$ is of great importance for the understanding of the structure and of the electronic configuration of the Mössbauer active atom, and from such data larger structures such as those of ion clusters or molecules can often be inferred. Nuclides with spins greater than $\frac{3}{2}$ generally yield sufficiently complex powder spectra so that these parameters can be obtained directly. For spin $\frac{3}{2}$ nuclides however single crystals are often needed, although. Ruby and Flinn [53] have suggested a method applicable to these nuclides when single crystals are not available. In this method one perturbs the Mössbauer spectrum by applying a large external field $H_{\text {ext }}$. The theoretical and experimental basis of the magnetic perturbation technique have been developed and its usefulness demonstrated by Collins and Travis $[54,55]$ for ${ }^{57} \mathrm{Fe}$. They calculated a series of typical spectra to enable $V_{z z}$ and $\eta$ to be determined in most diamagnetic iron compounds. Since polycrystalline samples are considered, the observed spectrum is the summation of spectra of all possible orientations $\theta$ of the efg main axis with respect to $H_{\text {ext }}=H_{\text {eff }}$. Therefore one observes bands rather than lines. For a given $\theta$ and assuming $\eta=0$ the energy level scheme is shown in figure 3 in which the resulting observable spectrum is also indicated. A typical experimental spectrum for a powder (integrating over all $\theta$ ) consists of a doublet and a triplet. When the doublet lies at higher velocities as in figure $3, V_{z z}$ is positive and vice versa.

This method applies not only to diamagnets but also to isotropic paramagnets, i. e. at sufficiently high temperature so that the parallel $\left(\chi_{\|}\right)$and perpendicu$\operatorname{lar}\left(\chi_{\perp}\right)$ susceptibilities are approximately equal and small and the magnetic field within the sample is virtually isotropic. For a paramagnet at low temperatures the situation would be rather more complex since the susceptibility may be very high and $\chi_{\|}$very different from $\chi_{\perp}$. For example in iron (II) phtalocyanine [56] $\chi_{\perp} / \chi_{i 1} \sim 10^{10}$ at $4.2 \mathrm{~K}$. Therefore $H_{\text {eff }}$ is very different from $H_{\text {ext }}$ in magnitude and direction. Determination of the sign of the efg must therefore be made at a temperature where either $H_{\text {ext }}$ (high temperature) or $H_{\mathrm{hr}}$ (low temperature) predominates. In $\mathrm{Fe}\left(\mathrm{ClO}_{4}\right)_{2} .6 \mathrm{H}_{2} \mathrm{O}$ Coey et al. [57] observed that $H_{\text {ext }}$ and $H_{\mathrm{hf}}$ cancel exactly at $30 \mathrm{~K}$. At that temperature the effect of $H_{\mathrm{ext}}$ will only be to broaden the lines through the anisotropic hyperfine interactions without

TABLE I

Values of the crystal field parameters $D$ and $E$ derived in several compounds from HFMS

\begin{tabular}{|c|c|c|c|c|}
\hline & Compounds & $\underline{\mathrm{cm}}^{-1}$ & $E \mathrm{~cm}^{-1}$ & References \\
\hline \multirow{2}{*}{$\mathrm{Fe}(\mathrm{II})$} & Rubredoxin & +4.4 & & [33] \\
\hline & $L=1,8$-naphthyridine & $<1$ & & [42] \\
\hline \multirow{7}{*}{$\mathrm{Fe}(\mathrm{III})$} & $\mathrm{FeCl}_{3}$ & +0.4 & & [38] \\
\hline & $\mathrm{Fe}: \mathrm{LiAl}_{5} \mathrm{O}_{9}$ & $-0.104(*)$ & & [43] \\
\hline & Tris (hexamethyldisilylaminato) $\mathrm{Fe}$ & -0.7 & & [44] \\
\hline & Mycobactin $\mathbf{P}$ & +0.34 & +0.088 & [45] \\
\hline & Hemin & +6 & & [46] \\
\hline & Haem proteins & \multicolumn{2}{|l|}{$\begin{array}{c}\text { from }+6 \\
\text { to }+15\end{array}$} & {$[47]$} \\
\hline & $\mathrm{Fe}^{3+}$ ion exchange sulfo-resin & \multicolumn{2}{|c|}{$E / D=0.15$} & {$[48]$} \\
\hline $\mathrm{Fe}(\mathrm{IV})$ & $\left(\mathrm{Fe}(\text { diars })_{2} \mathrm{Cl}_{2}\right)\left(\mathrm{BF}_{4}\right)_{2}$ & +23 & $\leqslant 3$ & [49] \\
\hline $\mathrm{Fe}(\mathrm{VI})$ & Ferrate ion & +0.11 & +0.02 & {$[50]$} \\
\hline \multirow[t]{2}{*}{$\mathrm{Eu}(\mathrm{II})$} & Eu hexammines & -0.020 & & {$[25]$} \\
\hline & Eu-Ca hexammines & +0.020 & & {$[29]$} \\
\hline
\end{tabular}

(*) Only the sign of $D$ was determined by HFMS. 


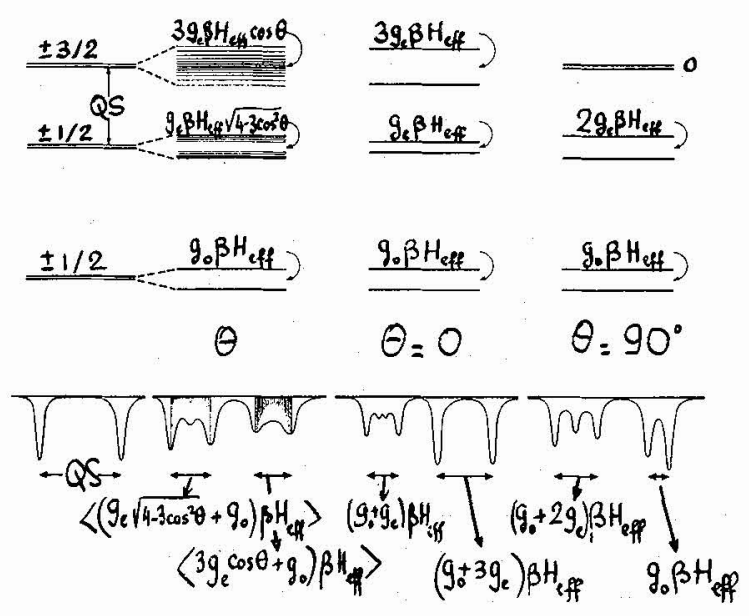

FIG. 3. - Nuclear level scheme and typical Mössbauer spectra obtained when $H_{\text {ext }}$ perturbs a quadrupole split polycrystalline sample $(\eta=0)$. For a diamagnet (or a paramagnet at high $T$ ), $H_{\text {eff }}=H_{\text {ext }}$ and the resulting spectrum consists of broad lines because of the random distribution of $\theta$. For a paramagnet at low $T$, the orientation (and the magnitude) of $H_{\text {eff }}$ may differ from that of $H_{\text {ext. }}$ The two extreme cases $\theta=0$ and $\theta=\pi / 2$ are shown. It is seen that narrow lines are observed and that measure of the ratio of the «doublet » and « triplet $»$ splittings may be an indication of the orientation of $H_{\text {eff }}$ with respect ot the efg axis.

splitting them. It is frequently observed at low temperatures that $H_{\mathrm{hf}}$ is along or perpendicular to the efg axis. Then $H_{\text {eff }}$ is no longer randomly distributed with respect to the efg axis and narrow resonance lines are observed [56], as shown in figure 3 for $\theta=0$ or $90^{\circ}$.

The determination of $\eta$ is less straightforward because the changes in the magnetically perturbed spectrum are minimal when $\eta$ varies between 0 and $\sim 0.5$. Also when $\eta$ approaches unity, there is a gradual change to mirror symmetry in the spectrum. Precise measurements with a very high external field should probably be obtained in compounds presenting very large quadrupole splittings such as those in the 4-5 $\mathrm{mm}$ range recently reported for $\mathrm{Fe}(\mathrm{II})[37,42$, 58,59 ] or $\mathrm{Fe}$ (III) [44] complexes.

The pioneering work of Collins and Travis gave impetus to several groups to examine iron compounds [60] and tin compounds $[61,62]$ using the magnetic perturbation technique with external fields ranging from 30 to 60 kOe approximately. Using calculated spectra by Collins and Travis [55] for ${ }^{57} \mathrm{Fe}$ and by Gibb [62] for ${ }^{119} \mathrm{Sn}$ nuclides it is possible to predict in advance the magnitude of the required field. As far as the orientation of $H_{\mathrm{ext}}$ is concerned, Lang [63] has shown that there is not significant difference in computing time between the longitudinal and transverse geometry. For a correct interpretation of spectra of powder samples care has to be taken to prevent preferential ordering. When the samples are not oriented completely randomly with respect to the optical axis of the experiment (i. e. when there is some degree of preferential crystal orientation as is frequently encountered if the crystal habit is that of plates, sheets or needles), significant differences from " random orientation 》 spectra are observed. Under these conditions the resultant spectra may have an appearance tending toward those for $\theta=0$ or $\theta=\pi / 2$ (Fig. 3), the amount of distortion depending on the degree of preferential orientation of the sample. Also Travis and Collins [64] have considered the influence of a Goldanskii-Karyagin (G. K.) effect on the shape of the magnetically perturbed spectra. They came to the important conclusion that failure to account for GK distortion can lead to incorrect evaluation of the efg tensor elements. For instance, several of the distorted spectra for $\eta=1$ appear to have a doublet and a triplet leading one to assign a sign to $V_{z z}$.

2.4.2 Electric field gradient as a probe for structural studies. - The precise knowledge of $V_{z z}$ and $\eta$ is a rich source of information in several domains. In view of the extensive literature in this field it is impossible to quote all results which have been obtained from the interpretation of magnetically perturbed Mössbauer spectra. Reiff [65] has recently surveyed the magnetic perturbation method for iron and tin coordination compounds. Let us briefly enumerate a few experiments of this type which are related to structure and bonding. An example is the study of ferrocene $\left(\left(\pi \mathrm{C}_{5} \mathrm{H}_{5}\right)_{2} \mathrm{Fe}\right)$ by Collins [54] who was able to make a choice between two previously suggested MO schemes for this compound, on the basis of the experimentally determined sign of the efg tensor, since the two theoretical models predicted opposite values of this parameter. Moreover, this study has also led to a clearer understanding of the metal orbitals used in the interaction with the cyclopentadienyl ring and accounts for the nearly complete collapse of the quadrupole interaction when ferrocene undergoes a one electron oxidation to the ferricinium ion $\left(\left(\pi \mathrm{C}_{5} \mathrm{H}_{5}\right)_{2} \mathrm{Fe}^{+}\right)$. In some cases the dominant contribution to the efg has been determined [66] : for example $V_{z z}$ for cis- and trans- $\mathrm{FeCl}_{2}\left(\mathrm{p}-\mathrm{MeO} \cdot \mathrm{C}_{6} \mathrm{H}_{4} \cdot \mathrm{NC}\right)_{4}$ has opposite signs indicating that the lattice contribution does not dominate the magnitude of the efg as previously assumed. A promising field seems also to be the study of ion coordination. Difficulties in distinguishing between different types of coordination with conventional technique (IR, NMR, susceptibility) can be removed by the magnetic perturbation technique $[59,67]$. For example it was assumed for a while that the large quadrupole splittings $(\sim 4 \mathrm{~mm} / \mathrm{s})$ observed in high spin iron (II) complexes. were associated with a pentacoordination [68, 69]. However even larger values have subsequently been found in eight-coordinate complexes [37, 42]. From recent magnetically perturbed Mössbauer studies $[58,65]$ it appears that both lattice contribution to the efg and covalency play an important role. Large quadrupole values are therefore not uniquely characteristic of a given coordination but depend on peculiarities of the particular coordination environment [59,70].

The same technique allows one to determine the ground state orbital wave function in a complex [56, 
71-73], at least when electrons are localized on the metal ion, $i$. e. when there is no significant contribution from the bonding electrons due to mixing of the metal and ligand orbitals [36]. Also of interest is the observation of a change of sign for $V_{z z}$ which may reflect a change of symmetry about the Mössbauer nucleus resulting in an orbital ground state reversal [57, 74-76] or a high-spin $\rightleftarrows$ low spin transition [32].

Finally the magnetic perturbation technique may provide an indication of the orientation of $V_{z z}$ and the effective field at the nucleus. Indeed the ratio of the triplet and doublet splittings (see Fig. 3) may be taken as a rough measure of $\theta[44,56,77]$.

At this point it is worth mentioning the determination by Uhrich et al. [78] of the sign of the efg at the tin site in an ordered smectic liquid crystal. A disc-shaped sample was heated at $90{ }^{\circ} \mathrm{C}$ in a magnetic field of $9 \mathrm{kOe}$ and then cooled in the field to room temperature. At this temperature the sample existed in the smectic $H$ phase and could be removed from the magnetic field without disturbing the molecular alignment and used as a single crystal in a zero-field Mössbauer experiment.

2.4.3. Magnetically induced quadrupole interaction. - A nucleus does not always experience an efg. In cubic symmetry for example contributions to the quadrupole interaction due to the nearest neighbor environment are not expected. However non vanishing quadrupole splittings have been observed in ferrous compounds in which the $\mathrm{Fe}^{2+}$ ion occupies a site of cubic symmetry. A characteristic feature is that the onset of the quadrupole interaction is simultaneous with magnetic ordering. It was first pointed out by Marshall [79] that the efg arises as a consequence of non zero exchange interaction, the effective magnetic field at the ion site acting through the spin orbit coupling to produce an asymmetrical charge distribution. The topic of magnetically induced quadrupole interaction (MIQI) has been discussed in several papers [8083]. In a cubic paramagnet the same argument holds when an external field is applied. For $H_{\text {ext }}$ along the (100) or (111) directions the major axis of the efg tensor is collinear with $H_{\text {ext }}$ and from symmetry arguments it is clear that the asymmetry parameter is zero. As predicted by Ham [79] the Mössbauer spectrum of $\mathrm{MgO}: \mathrm{Fe}^{2+}[18,84]$ in an external field of $50 \mathrm{kOe}$ shows that the MIQI has equal magnitude but opposite signs in the (100) and (111) directions. However different values of MIQI when $H_{\text {ext }}$ rotates from one direction to the other are observed in $\mathrm{CaO}$ : $\mathrm{Fe}^{2+}$ [21] and $\mathrm{KMgF}_{3}: \mathrm{Fe}^{2+}[85]$ due to dynamic Jahn-Teller coupling [86]. A field induced efg has also been observed at the $\mathrm{Yb}$ nucleus in the cubic intermetallic $\mathrm{YbPd}_{3}$ [39] which remains paramagnetic down to $1.4 \mathrm{~K}$. It is worth pointing out that the MIQI can be used to get a rather accurate estimate of the nuclear quadrupole moment $Q$ of the nucleus since one does not have to bother about the lattice contribution to the efg which arises solely from the electronic charge distribution. For ${ }^{57} \mathrm{Fe}$ this method gives

$$
Q=+0.21 \text { b [87] }
$$

Finally it should be kept in mind that second order terms in $\mathscr{H}_{\mathrm{SH}}$ can give rise to pseudo contributions such as the pseudo nuclear quadrupole interaction and the pseudo nuclear Zeeman interaction [7]. These terms may not be negligible when an external field is applied to systems having closely spaced ground and excited electronic states $[21,85]$.

3. Intramolecular magnetic order. - 3.1 EXCHANGE HaMiLTONIAN. - Magnetic ordering in solids can take place in two ways. It can have a long range character through the lattice (intermolecular ordering) as in usual ferro-, ferri- or antiferromagnets. But it can also have a discrete character (intramolecular ordering). Although intramolecular ferromagnetism has been shown to exist [88] the most common type of intramolecular ordering in chemical compounds is intramolecular antiferromagnetism [89, 90]. It occurs in polynuclear complexes in which a small number ( $\sim 2$ to 8 ) of transition metal ions are coupled to each other in a cluster by strong exchange interactions, while the clusters are magnetically isolated from each other in the solid. If one or more of the metal ions are suitable for Mössbauer spectroscopy and if the externally applied field becomes comparable to the intramolecular exchange energy, an estimate of the exchange integrals can be obtained.

Within a cluster, metal-metal interactions act through superexchange interactions which can simply be described in terms of the classical exchange Hamiltonian [90]

$$
\mathfrak{H}_{\mathrm{ex}}=-2 \sum_{j>i=1}^{n} J_{i j} \mathbf{S}_{i} \mathbf{S}_{j}
$$

where the sum is taken over all interacting pairs in the cluster and $J_{i j}$ is the exchange integral between the $i$ th and $j$ th atom, with spins $S_{i}$ and $S_{j}$. It is possible to write down the eigenvalues of eq. (17), using the vector model [91] :

$$
2 \mathbf{S}_{i} \cdot \mathbf{S}_{j}=S_{i j}\left(S_{i j}+1\right)-S_{i}\left(S_{i}+1\right)-S_{j}\left(S_{j}+1\right)
$$

where $\mathbf{S}_{i j}=\mathbf{S}_{i}+\mathbf{S}_{j}$. Sinn [90] has tabulated the eigenvalues of $\mathscr{H}_{\mathrm{ex}}$ for different values of $n, S_{i}, S_{j}$ and $J_{i j}$.

Let us consider the simple case of binuclear clusters. The spin-spin Hamiltonian reduces to :

$$
\mathscr{H}_{\mathrm{ex}}=-2 J_{12} \mathbf{S}_{1} \cdot \mathbf{S}_{2}
$$

and the energy levels appropriate to this Hamiltonian are

$E\left(S_{\mathrm{T}}\right)=-J\left(S_{\mathrm{T}}\left(S_{\mathrm{T}}+1\right)-S_{1}\left(S_{1}+1\right)-S_{2}\left(S_{2}+1\right)\right)$

where $J=J_{12}$ and $\mathbf{S}_{\mathrm{T}}=\mathbf{S}_{1}+\mathbf{S}_{2}\left(S_{\mathrm{r}}\right.$ has allowed values $\left.S_{1}+S_{2}, S_{1}+S_{2}-1, \ldots\left|S_{1}-S_{2}\right|\right)$. The 
effect of an external field is represented by adding a term $g \beta \mathbf{H}_{\text {ext }} \cdot \mathbf{S}_{\mathbf{T}}$ to eq. (18), with $g$ being the Landé splitting factor. Defining the $z$-axis along $\mathbf{H}_{\text {ext }}$, the energy levels are split into $2 S_{\mathrm{T}}+1$ sublevels. The eigenvalue equation is :

$$
E=E\left(S_{\mathrm{T}}\right)+g \beta H_{\mathrm{ext}} M_{\mathrm{S}_{\mathrm{T}}}
$$

and if $S_{1}=S_{2}=S$,

$E=-J\left(S_{\mathrm{T}}\left(S_{\mathrm{T}}+1\right)-2 S(S+1)\right)+g \beta H_{\mathrm{ext}} M_{\mathrm{S}_{\mathrm{T}}}$.

This situation is represented in the insert of figure 4 . For two $S=\frac{5}{2}$ ions antiferromagnetically coupled $(J<0)$, the ground state has $S_{\mathrm{T}}=0$ (singlet state). A

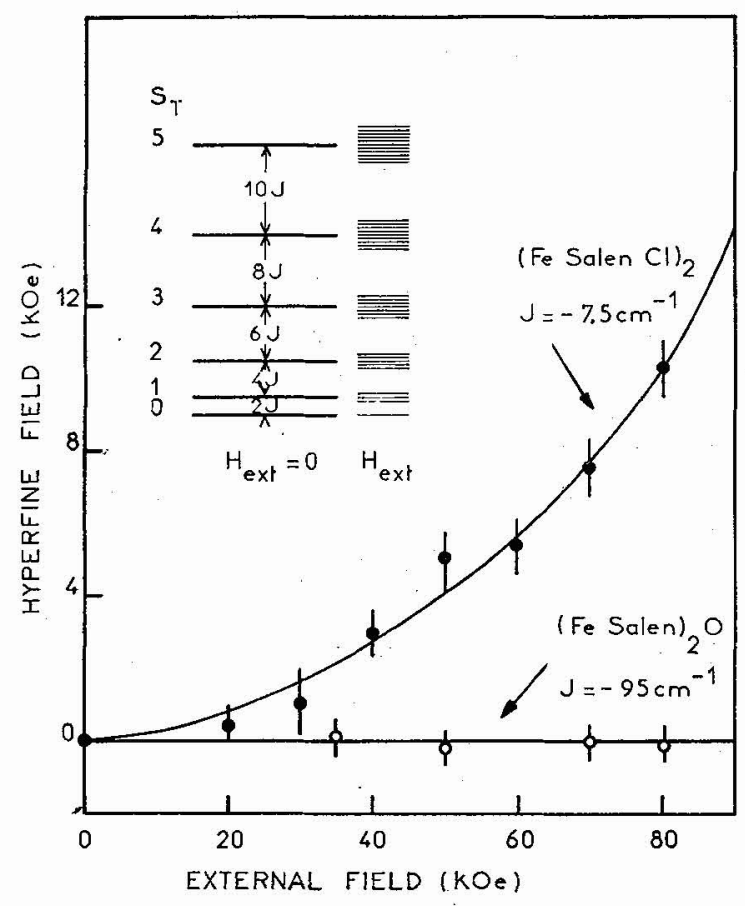

FIG. 4. - $\mathrm{H}_{\text {he }}$ in $(\mathrm{Fe} \text { salen } \mathrm{Cl})_{2}$ and (Fe salen $)_{2} \mathrm{O}$ plotted as a function of $H_{\text {ext }}$ at $T=4.2 \mathrm{~K}$. In the insert is shown the energy level diagram for two $S=5 / 2$ ions coupled with $J<0$ (adapted from ref. [92]).

material consisting of such clusters is therefore diamagnetic at low temperatures. Magnetism will appear only at higher temperatures when excited states (the first excited level is distant from $2 J$ ) become populated.

\subsection{DETERMINATION OF THE EXCHANGE INTEGRAL. -}

Lechan et al. [92] have made a detailed high field Mössbauer study of the binuclear ferric complex (Fe salen $\mathrm{Cl})_{2}$ where salen is $\mathrm{N}-\mathrm{N}^{\prime}$ ethylenebis (salicyldiminato). Calculation of the magnetic hyperfine interaction leads to a field and temperature dependence of $H_{\mathrm{hf}}$ given by :

$$
\begin{gathered}
\sum_{S_{\mathrm{T}}} \sum_{M_{S_{\mathrm{T}}}}\left(A / \delta_{\mathrm{n}} \beta_{\mathrm{n}}\right) M_{\mathrm{S}_{\mathrm{T}}} \times \\
H_{\mathrm{hE}}=\frac{\times \exp \left(-\left(J S_{\mathrm{T}}\left(S_{\mathrm{T}}+1\right)-g \beta H_{\mathrm{ext}} M_{\mathrm{S}_{\mathrm{T}}}\right) / k T\right)}{\sum_{S_{\mathrm{T}}} \sum_{M_{S_{\mathrm{T}}}} \exp \left(-\left(J S_{\mathrm{T}}\left(S_{\mathrm{T}}+1\right)-g \beta H_{\mathrm{ext}} M_{\mathrm{S}_{\mathrm{T}}}\right) / k T\right)} .
\end{gathered}
$$

Thus the hyperfine interaction depends only on two parameters $A / g_{\mathrm{n}} \beta_{\mathrm{n}}$ and $J$ which can be determined by measuring $H_{\mathrm{hf}}$ as a function of $H_{\mathrm{ext}}$ and $T$. The field dependence at $4.2 \mathrm{~K}$ is shown in figure 4 . For comparison similar measurements in ( $\mathrm{Fe}$ salen) ${ }_{2} \mathrm{O}$ [92] are also shown in this figure. The solid lines are the best fit assuming $J=-7.0 \mathrm{~cm}^{-1}$ and $-95 \mathrm{~cm}^{-1}$, respectively, in excellent agreement with susceptibility data. It is seen that in ( $\mathrm{Fe}$ salen $)_{2} \mathrm{O}$, the antiferromagnetic coupling is so strong that it is not perturbed by an external field as high as $80 \mathrm{kOe}$ and no hyperfine field is observed, i. e. $H_{\text {eff }}=H_{\text {ext }}$ [92-95]. In the less coupled $((\mathrm{Fe} \text { salen }) \mathrm{Cl})_{2}$ a small field dependent hyperfine field is induced [92].

It seems an almost safe rule to state that the absence of a hyperfine field in magnetically perturbed spectra is diagnostic of dimeric structure with intramolecular antiferromagnetic ordering [96, 97] providing other data rule out the presence of diamagnetic low spin states. For example such a criterion has been decisive in establishing that $\mathrm{Fe}$ (salen) $\mathrm{Cl}, \frac{1}{2} \mathrm{CH}_{3} \mathrm{NO}_{2}$ was dimeric [98] rather than monomeric as suggested by room temperature susceptibility and infrared measurements. High field Mössbauer evidence for a dimeric structure was also found in several quinoxaline 2, 3 dithiolate complexes of iron [99]. Fitzsimmons and Johnson (100) have noted however that the above stated rule does not hold in cases where the ligand field parameter $D$ is comparable to $J$, since the effect of $D$ is to mix higher states into the $M_{\mathrm{S}_{\mathrm{T}}}=0$ ground state. Murray [101] has recently reviewed in detail the properties of the binuclear oxo-bridged iron (III) complexes, covering the Mössbauer results. A survey of Mössbáuer data can also be found in ref. [64].

Complexes having three [102, 103] four or more [104] metal ions have been studied by HFMS. These studies seem promising in the sense that they allow a test of exchange models to be made on discrete systems rather than infinite lattices. Another very fruitful domain of investigation has been found in the series of iron-sulfur proteins (for a review see ref. [105-107]). These proteins have biologically important redox properties due to antiferromagnetically coupled $\mathrm{Fe}^{3+}-\mathrm{Fe}^{3+}$ clusters in their oxygenated form and $\mathrm{Fe}^{2+}-\mathrm{Fe}^{3+}$ in their reduced form [108, 109].

4. Magnetically ordered compounds. - 4.1 ANISOTROPY AND EXCHANGE. - Let us now turn to infinite lattice magnetic ordering (intermolecular). In magnetically ordered compounds the direction of the ion magnetic moments is the result of the competition between three terms: the exchange energy (represented by an effective exchange molecular field $H_{\mathrm{E}}$ ) - 
the anisotropy energy (anisotropy field $H_{\mathrm{A}}$ ) and the external field $H_{\text {ext }}$ if any [110]. It is well known that magnetically split Mössbauer spectra provide information on spin directions in several respects :

i) The relative line intensities depend upon the relative orientation of $H_{\text {eff }}$ with the direction of observation through polarization effects.

ii) The line positions depend upon the magnitude of $H_{\mathrm{eff}}$, i. e. $H_{\mathrm{ext}}$ and $H_{\mathrm{hr}}$. In the presence of a quadrupole interaction (assumed axial), this dependence is rather complicated since the angle between $H_{\text {eff }}$ and the efg axis varies with $H_{\text {ext }}$.

The possibility of determining the magnitude of the anisotropy in an antiferromagnetic uniaxial single crystal by means of the HFMS was first suggested by Cinader et al. [111] and demonstrated in powders by Beckmann et al. $[112,113]$, using arguments described in i). Since in antiferromagnets $\chi_{\perp}>\chi_{\| i}$, the external field tends to rotate the spins in a direction perpendicular to it. But it is only when $H_{\text {ext }}$ reaches a critical value $H_{\mathrm{cr}}=\sqrt{2 H_{\mathrm{E}} H_{\mathrm{A}}}$ that rotation takes place. The critical field was found to be $27 \mathrm{kOe}$ in $\mathrm{FePO}_{4}$ [112], much higher than $50 \mathrm{kOe}$ in $\mathrm{ZnFe}_{2} \mathrm{O}_{4}$ [113] $\mathrm{FeSn}_{2}$ [113] or $\mathrm{Fe}: \mathrm{CoO}$ [114] due to a large anisotropy energy. Moreover Beckmann et al. [112] measured the sign of the anisotropy energy by making use of ii). The sign is said to be positive when the spins are parallel to the symmetry axis (as in $\mathrm{FePO}_{4}$ ) and negative in the perpendicular case. Also HFMS can be uniquely useful when one looks for the specific contributions of an ion to the magneto-crystalline anisotropy of materials. One knows that the total anisotropy is generally made up of the sum of the individual singleion contributions. Fletcher et al. [115] have measured the $\mathrm{Fe}^{3+}$ contribution to the anisotropy in $\mathrm{Fe}_{3} \mathrm{O}_{4}$ and $\mathrm{Fe}_{3-x} \mathrm{Ti}_{x} \mathrm{O}_{4}$, using the relative sublattice magnetizations determined from HFMS.

4.2 Behavior of MAgNetically ORDERed COMPOUNDS IN AN EXTERNAL FIELD. - 4.2.1 Ferromagnets. - In a ferromagnet the effective field as a function of $H_{\text {ext }}$ is given by :

$$
\mathbf{H}_{\mathrm{eff}}=\mathbf{H}_{\mathrm{hf}}+\mathbf{H}_{\mathrm{cxt}}-\mathrm{DM}
$$

where $\mathbf{D M}$ is the demagnetization field. Therefore when $H_{\text {ext }}$ is switched on, $H_{\text {eff }}$ will change its magnitude from $\left|H_{\mathrm{hf}}\right|$ to $\left|H_{\mathrm{hf}}\right| \pm\left|\left(H_{\text {ext }}-\mathrm{D} M\right)\right|$, depending on whether $H_{\mathrm{hf}}$ is parallel or antiparallel to the magnetization. The demagnetizing field can be quite large : it reaches $22 \mathrm{kOe}$ for a thin iron foil magnetized with $H_{\text {ext }}$ perpendicular to its plane [116]. Heberle [5] has discussed the difficulties one may encounter when one uses this method to determine the sign of $H_{\mathrm{hr}}$. A better method developed by Blum and Grodzins [116] is based on the use of circularly polarized $\gamma$-rays by placing both source and absorber in $H_{\text {ext }}$. Apart from sign determination, HFMS may confirm the ferromagnetic character of a material and help to determine the contributions to $H_{\mathrm{hf}}[117,118]$.
4.2.2 Antiferromagnets. - Antiferromagnets are of particular interest because upon application of $H_{\text {ext }}$ they display a wide variety of phase transitions in addition to the paramagnetic (P) to antiferromagnetic (AF) transition at the Néel point $T_{\mathrm{N}}$. A comprehensive review of the HFMS of these magnetically induced phase transitions has been recently published [119]. Following Frankel's discussion [119] let us apply $H_{\text {ext }}$ along the easy axis of magnetization of a uniaxial antiferromagnet at $T$ below $T_{\mathrm{N}}$. When $H_{\text {ext }}$ reaches a critical value, $H_{\mathrm{SF}}$, a first-order phase transition occurs and the spins rotate in a direction perpendicular to $H_{\mathrm{ex} \text {. }}$. This phase is known as the spin-flop (SF) phase and the transition to this phase as the spin-flop transition. If $H_{\mathrm{ext}}$ is increased beyond $H_{\mathrm{SF}}$ the spins tip toward each other until $H_{\mathrm{ext}}=H_{\mathrm{p}}$ induces a second-order phase transition to the $\mathrm{P}$ phase in which the spins are parallel to the easy magnetization axis. $H_{\mathrm{SP}}$ and $H_{\mathrm{P}}$ are determined by $H_{\mathrm{A}}$ and $H_{\mathrm{E}}$, and since both are temperature dependent, the critical magnetic fields $H_{\mathrm{SP}}$ and $H_{\mathrm{P}}$ are also temperature dependent, and a phase diagram can be constructed (upper part of Fig. 5). If now $H_{\text {ext }}$ is applied perpendicular to the easy axis there is no SF transition. $H_{\text {ext }}$ causes the spins to tip toward each other until the critical field,

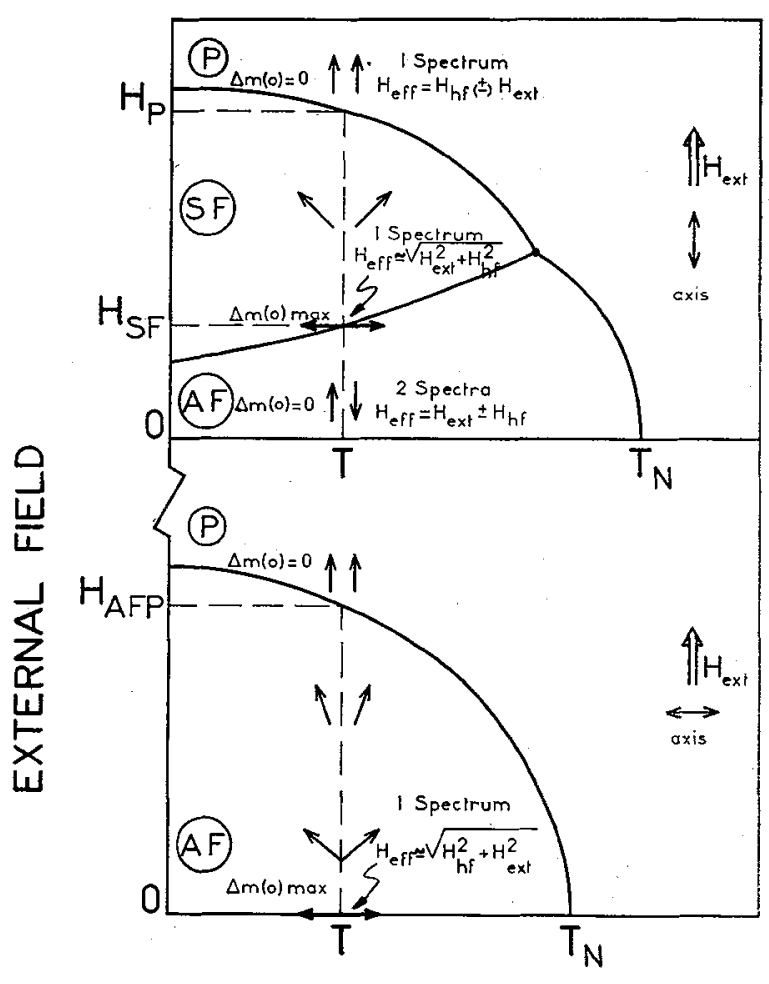

TEMPERATURE

FIG. 5. - Schematic phase diagram for uniaxial, easy axis single crystalline antiferromagnet, for $H_{\text {ext }}$ parallel (above) and perpendicular (below) to the easy axis. In each case the intensity of the $\Delta m=0$ lines (labelled $\Delta m(0)$ ) is indicated (for $\gamma$-ray propagation direction parallel to $H_{\text {ext }}$ ) as well as details of the observed Mössbauer spectra (adapted from ref. [120]). 
$H_{\mathrm{AFP}}$, causes a second-order transition to the $\mathrm{P}$ phase where the spins are perpendicular to the easy axis (lower part of Fig. 5). Numerous materials with a range of values for $H_{\mathrm{A}}$ and $H_{\mathrm{E}}$ have been studied by HFMS, exploring part of the phase diagram of figure 5. Iron compound studies include hematite $[121,122], \mathrm{FeCl}_{2}$ and $\mathrm{FeBr}_{2}$ [123], $\mathrm{FeCO}_{3}$ [124], $\mathrm{NEt}_{4} \mathrm{FeBr}_{4}$ [125], $\mathrm{Fe}_{2} \mathrm{Ti}$ [126], $\mathrm{MnF}_{2}: \mathrm{Fe}^{2+}$ [127], $\mathrm{FeCl}_{3} .6 \mathrm{H}_{2} \mathrm{O}$ [128], $\mathrm{FeCl}_{3}$ [129], $\mathrm{FeCl}_{2} .2 \mathrm{H}_{2} \mathrm{O}$ [130], $\beta \mathrm{FeF}_{3} .3 \mathrm{H}_{2} \mathrm{O}$ [131], $\mathrm{AuFe}[118,132], \gamma$-FeOOH [133], Fe doped $\gamma$-AlOOH, $\mathrm{ZnAl}_{2} \mathrm{O}_{4}$ and $\mathrm{KAl}_{3}(\mathrm{OH})_{6}\left(\mathrm{SO}_{4}\right)_{2} \quad$ [134] and $\mathrm{K}_{2} \mathrm{FeO}_{4}$ [135]: External fields have also been used to study ${ }^{151} \mathrm{Eu}$ antiferromagnets such as Gd-doped and La-doped EuSe [136], the intermetallics $\mathrm{EuCu}_{2}$ and $\mathrm{EuAl}_{4}$ [40] and equiatomic PdEu [137]. When single crystals are used, narrow lines are observed independant of the value of $H_{\mathrm{A}}$. This will also be true for weakly anisotropic polycrystalline materials. But if $H_{\mathrm{A}} \gg H_{\text {ext }}$, in each randomly oriented crystallite the spins remain aligned in the easy direction and $H_{\text {eff }}$ ranges from $H_{\text {ext }}-H_{\text {hf }}$ to $H_{\text {ext }}+H_{\mathrm{hf}}$, i. e. it results in a broadening of the lines $[126,138]$.

4.2.3 Helimagnets. - The only helimagnet studied by HFMS seems to be anhydrous $\mathrm{FeCl}_{3}$ [129]. When $H_{\text {ext }}$ is applied along the hexagonal $c$-axis of the crystal so that it makes various angles with the magnetic spins, the lines of the spectrum broaden owing to the vector addition of $H_{\mathrm{ext}}$ and the randomly oriented $H_{\mathrm{hf}}$ (of course broadening would also be observed for a powder). Increasing $H_{\text {ext }}$ above $15 \mathrm{kOe}$ destroys the spiral structure and a spectrum reflecting the presence of two sublattices is observed. Further increase of $H_{\text {ext }}$ above $40 \mathrm{kOe}$ causes a spin-flop.

4.2.4 Ferrimagnets. - HFMS has been the method of choice for a large number of studies of ferrimagnets. This comes from the ability of distinguishing the two sublattices $A$ and $B$ in these materials upon application of $H_{\text {ext }}$. According to Néel's model of ferrimagnetism, antiparallel moments have unequal magnitude giving rise to a net resultant moment. When $H_{\text {ext }}$ is applied, the effective field on each sublattice $A$ and $B$ is :

$$
H_{\text {eff }}(\mathrm{A}, \mathrm{B})=H_{\mathrm{hf}}(\mathrm{A}, \mathrm{B}) \pm H_{\mathrm{ext}} .
$$

When $H_{\text {ext }}$ is parallel to the direction of $\gamma$-ray propagation the $\Delta m=0$ lines vanish and the resulting spectrum consists of the superposition of two four line spectra with $H_{\text {eff }}$ given by eq. (24). Such a behavior was observed in $\mathrm{NiFe}_{2} \mathrm{O}_{4}$ subjected to $H_{\text {ext }}=70 \mathrm{kOe}$ [139] and constitutes a definite proof of its collinear structure. The magnetic moments of some spinel ferrites are not well understood in terms of Néel's ferrimagnetism. In particular, chromium containing spinels have magnetic moments one order of magnitude smaller than the value predicted from this collinear model [140, 141]. Several possible explanations for this reduction have been proposed [142]. In particular Yafet and Kittel [143] extended the Néel theory by allowing canted spin arrangements. Under these conditions eq. (23) becomes

$$
\begin{gathered}
H_{\mathrm{eff}}(\mathrm{A}, \mathrm{B})= \\
=\left(H_{\mathrm{ext}}^{2}+H_{\mathrm{hf}}^{2}(\mathrm{~A}, \mathrm{~B})-2 H_{\mathrm{ext}} H_{\mathrm{hf}}(\mathrm{A}, \mathrm{B}) \cos \theta_{\mathrm{A}, \mathrm{B}}\right)^{1 / 2}
\end{gathered}
$$

where $\theta_{\mathbf{A}, \mathbf{B}}$ are the angles between the spins on sublattices $\mathrm{A}, \mathrm{B}$ and $H_{\text {ext }}$. From eq. (25) these angles may be deduced. Their value can also be compared to that derived from the observed intensity of the $\Delta m=0$ lines (which depends on $\theta_{\mathrm{A}, \mathrm{B}}$ ). Such an analysis brought evidence for a canted spin arrangement in $\mathrm{NiFe}_{0.3} \mathrm{Cr}_{1.7} \mathrm{O}_{4}$ [139], in $\mathrm{Zn}$ substituted Ni [144-147] and $\mathrm{Co}$ [148] ferrites.

Some knowledge of the importance of the magnetocrystalline anisotropy is needed for a correct interpretation of Mössbauer spectra. Indeed the disappearance of the $\Delta m=0$ lines for a Néel ferrimagnet depends on the anisotropy of the material. In weakly anisotropic $\mathrm{NiFe}_{2} \mathrm{O}_{4}$ it occurs at $H_{\text {ext }}=12 \mathrm{kOe}$ [139] while in $\mathrm{FeGaO}_{3}$ [149] and $\mathrm{AlFeO}_{3}$ [150] fields of the order of $100 \mathrm{kOe}$ were needed. Therefore a canted spin structure could be mistakenly inferred from a wrong interpretation of the high field Mössbauer data.

Another major domain of interest investigated through HFMS is cation distribution among different sites by taking advantage of the possibility of separating the sublattices hyperfine fields [144-148, 151-164]. Also, in favorable structures it is possible to determine if the arrangement of a magnetic ion and a non magnetic substitution in equivalent site is random [165]. But the intensity ratios of the lines are proportional to the ratio of the number of $\mathrm{A}$ and $\mathrm{B}$ site ions, provided that the recoilless fraction, $f$, is the same for the two sites. The validity of this assumption has been questioned for $\mathrm{Fe}_{3} \mathrm{O}_{4}$ and $\mathrm{YIG}$ [166]. It was found valid at $0 \mathrm{~K}$ but differences of $6 \%$ were observed at room temperature. Therefore the relative occupation numbers cannot be determined simply from line area measurements at room temperature but must be calculated from data extrapolated to $0 \mathrm{~K}$.

Finally, similarly to the technique used for liquid crystals [78], magnetically oriented absorbers simulating a single crystal, can be fabricated by allowing a mixture of fresh epoxy resin and powder sample to harden in a magnetic field produced by a conventional electromagnet. The zero-field Mössbauer spectra of these partially or totally oriented absorbers are quite similar to Mössbauer spectra recorded with an external fields and provide information on anisotropy and spin configuration $[167,168]$.

4.2.5 Superparamagnets. - Ultrafine particles of ferro and antiferromagnets behave as paramagnets below the magnetic ordering temperature. This is because the thermal energy at the temperature of the experiment is comparable to the energy barrier prevent. 
ing spontaneous reversal of the magnetization. Therefore due to relaxation between the various easy directions of magnetization the hyperfine field observed by Mössbauer spectroscopy collapses. However by applying an external magnetic field, the magnetic moment of the particle is polarized by the field and the Zeeman pattern is restored, because $H_{\text {ext }}$ favors one orientation of the magnetization. The magnetization $M$ of a non-interacting assembly of identical particles of moment $\mu$ is given by the classical Langevin function :

$$
M=M_{\mathrm{S}}\left[\operatorname{coth}\left(\frac{\mu H_{\mathrm{ext}}}{k T}\right)-\frac{k T}{\mu H_{\mathrm{ext}}}\right] .
$$

The above behavior has been observed in fine particles of $\mathrm{NiFe}_{2} \mathrm{O}_{4}$ [169], $\mathrm{Ni}$ [170], $\alpha-\mathrm{Fe}_{2} \mathrm{O}_{3}$ [171], $\mathrm{Fe}_{3} \mathrm{O}_{4}$ [172] and in frozen ferric perchlorate solutions [173]. In $\gamma-\mathrm{Fe}_{2} \mathrm{O}_{3}$, Coey et al. [174-175] have found by applying $H_{\text {ext }}=50 \mathrm{kOe}$ that ultra-fine particles $(\sim 60 \AA)$ have a core with much the same cation and spin arrangement as bulk $\gamma-\mathrm{Fe}_{2} \mathrm{O}_{3}$ but with a surface layer in which the iron spins are canted from their usual direction.

4.2.6 Amorphous magnets. - Up to now few high field Mössbauer studies of amorphous magnets have been performed. Bukrey et al. [176] have suggested the possibility of ferrimagnetic order in clusters of iron ions precipitated in an alkali-borate glass. Of considerable interest is a new spin structure called speromagnetism proposed by Coey and Readman [177] to account for the freezing of spins with random orientations observed at low $T$ in ferric gel and which, according to these authors, is likely to exist in a great number of amorphous compounds. They have calculated a spin-flop field of $100 \mathrm{kOe}$. Additional results pertaining to such structures are to be reported and discussed elsewhere in the conference proceedings [178].

5. Metals, alloys and intermetallic compounds. There are two situations associated with the magnetic behavior of alloys of magnetic atoms in metallic matrices. First the magnetic atom is present at high enough concentrations so that magnetic ordering takes place through exchange interaction. The second situation is that of a sufficiently dilute alloy with non interacting impurities. In this section we will concentrate on the first case. High field studies were essentially directed towards the following goals :

5.1 PROPORTIONALITY BETWEEN HYPERFINE FIELD AND BULK MAGNETIZATION. - The hyperfine field and the bulk magnetization were found accurately proportional in Fe-Pd alloys [179]. In iron metal application of an intense $H_{\text {ext }}(135 \mathrm{kOe})$ indicated a change of magnetization with the applied field equivalent to a susceptibility $\chi=2 \pm 7 \times 10^{-5} \mathrm{emu} / \mathrm{cc}$, while magnetization measurements give $\chi \leqslant 4 \times 10^{-5}$ [180].
5.2 CONTRIBUTIONS TO THE HYPERFINE FIELDS : in metallic systems $H_{\mathrm{hf}}$ may be considered to have three main sources:

i) core polarization ;

ii) local conduction electron polarization ;

iii) neighbor effects.

For instance at ${ }^{156} \mathrm{Gd}$ nuclei in $\mathrm{YAl}_{2}, \mathrm{YbAl}_{2}$ and A1, Frankel [181] has estimated contribution ii) to be $+140 \mathrm{kOe}$. In Gd metal this contribution is almost twice as large, due to a larger charge density at the Gd nucleus. In a high field Mössbauer study of Europium intermetallics, Nowik et al. [40] have evaluated the three contributions and correlated the first two contributions to the isomer shift. In Ni-Pd alloys Tansil et al. [182] observed that $H_{\mathrm{hf}}$ at the ${ }^{61} \mathrm{Ni}$ nucleus is concentration dependent : it increases from its negative value in pure $\mathrm{Ni}(-76 \mathrm{kOe})$ to a large positive value near the $\mathrm{Pd}$ rich end $(+173 \mathrm{kOe})$. These results indicate at least two contributions of opposite sign to $H_{\mathrm{hf}}$. It is indeed the case with the contributions i) and ii) being negative while the contribution iii) from $\mathrm{Pd}$ neighbors is positive and its magnitude depends on the local environment of a $\mathrm{Ni}$ atom. Measurements with $H_{\text {ext }}$ in alloys containing $50-99.5$ at. \% Pd show the presence of a distribution of hyperfine fields.

In several alloys application of an external field has given evidence for the absence of magnetic moment associated with some atoms as for $\mathrm{Fe}$ atoms in FeAl [183, 184], CoAl [184], NiAl [184], Fe ${ }_{2} \mathrm{Ti}$ [126] and $\mathrm{Fe}_{1-x} \mathrm{Co}_{x} \mathrm{~S}_{\mathrm{i}}$ [185] alloys. These results are related to the near neighbor environment of the iron atoms. A similar behavior has been observed at Gd nuclei in $\mathrm{GdFe}_{2}$ [186].

5.3 Clustering is frequent in alloy metallurgy and the growth of the precipitates can easily be followed with the Mössbauer technique. The use of an external field has been an aid in the identification of spectral features in $\mathrm{CuFe}$ [187-188], CuNiFe [188-190], Alnico [191] and FeAl [192] alloys.

6. Dilute alloys. - 6.1 LOCAL MOMENTS. - Let us now consider the case of a sufficiently dilute alloy where impurity interactions are negligible. This topic has recently aroused interest among physicists of various disciplines and HFMS has proved a very powerful tool in relation with other hyperfine techniques. Comprehensive reviews have been published recently [193-198]. These investigations were initiated in the early sixties by susceptibility measurements of dilute solutions of $\mathrm{Fe}$ in various transition metal alloys [199], rapidly followed by HFMS studies $[2-4,200]$. Some of the alloys showed an essentially temperature independent susceptibility, i. e. the iron atom did not carry a moment. But in other alloys, a Curie-Weiss temperature dependence was observed indicating that the $\mathrm{Fe}$ impurity was associated with a moment which is local in the sense that each Fe atom 
acts at low temperatures as a paramagnet in an external field. One can therefore expect a Brillouin type dependence of the field on temperature, that is, one may write :

$$
H_{\mathrm{hf}}=H_{\mathrm{hf}}^{S} B_{J}\left(\mu H_{\mathrm{ext}} / k T\right)
$$

where $J$ is the spin associated with the impurity and $\mu$ the localized magnetic moment. This analysis was first suggested by Craig et al. [2] and subsequently followed by many other experimentalists in the interpretation of their high field Mössbauer data. In a Mössbauer experiment, large values of $H_{\mathrm{ext}} / T$ give $H_{\mathrm{hf}}^{S}$ while for low values

$$
H_{\mathrm{hf}} \sim H_{\mathrm{hf}}^{\mathrm{s}} \frac{J+1}{3 J}\left(\mu H_{\mathrm{ext}} / k T\right) .
$$

The initial slope of $H_{\mathrm{hf}}$ versus $\left(H_{\mathrm{ext}} / T\right)$ gives the product $(J+1) \mu / 3 J$ and one chooses the $J$ values which fit best the experimental data, as illustrated in figure 6 for PdFe [2]. One notes that the method is not a very sensitive way to determine $J$. Nevertheless Craig et al. [2] concluded that $J=6.5 \pm 1.5$, i. e. $\mu$ associated with each $\mathrm{Fe}$ impurity is $12.6 \pm 0.4 \beta$. The magnitude of such a giant moment $\mu$. reflects the polarizability of the $\mathrm{Pd}$ matrix.

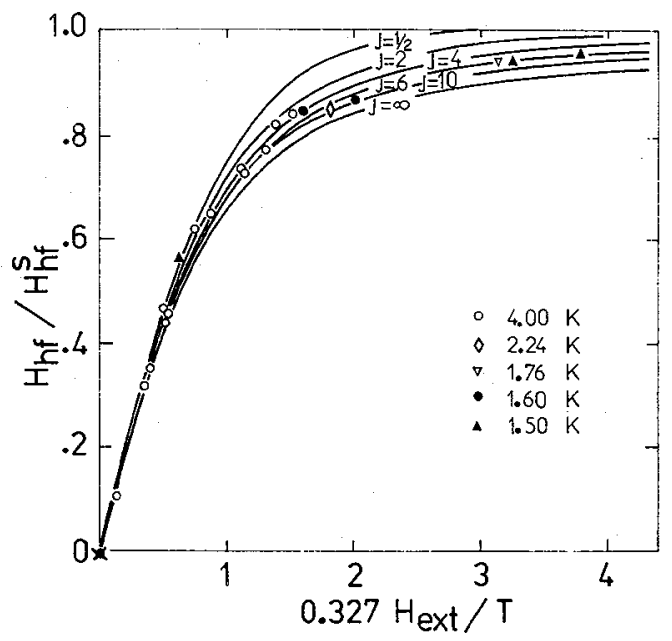

FIG. 6. - Reduced $H_{\text {hr }}$ observed in $\mathrm{Pd}^{57} \mathrm{Fe}$ plotted as a function of $H_{\text {ext }} / T$. The solid curves are Brillouin function for various values of spin (after ref. [2]).

It should be noted that the saturation value of the hyperfine field found in the preceding experiment is only $-295 \mathrm{kOe}$, i. e. it corresponds to $\sim 2 \beta$. This is not in contradiction with the observation of a giant moment, because, as emphasized by Freeman [201] in a Mössbauer experiment, $H_{\mathrm{hf}}^{S}$ measures the spin of the iron nucleus while the temperature and field dependence of $H_{\mathrm{hf}}$ relates to the total local spin. Giant moments have been observed not only for iron impurities in $\mathrm{Pd}[2,202]$ but also in $\mathrm{Pt}[2,202]$ with a moment of $6.5 \beta$ per iron atom, in $\mathrm{NiCu}$ alloys [203], in $\mathrm{Ni}_{3} \mathrm{Ga}$ [204-206] and in $\mathrm{Ni}_{3} \mathrm{Al}$ [206]. In these last three nearly ferromagnetic binary alloys, the moments are found to be concentration dependent and values up to $20 \beta, 39 \beta$ and $84 \beta$ respectively have been reported. It is likely that still higher values may be observable at compositions very close to the critical composition where the alloy becomes ferromagnetic [206]. A localized moment has been observed for $\mathrm{Fe}$ in Iridium [207] but the quality of the fit did not allow an independent determination of $\mu$. The high field behaviour of iron impurities in chromium has been interpreted by Herbert et al. [208] in terms of an exchange field produced on the Fe localized moments by the $\mathrm{Cr}$ spin density wave, while Frankel and Blum [209] suggested an alternate model due to Housley and Dash [210] which might also be used to understand the hyperfine interactions in this system.

An interesting question which has been considered was the elucidation of the mechanism by which the impurity ion acquires a localized moment. The iron doped $\mathrm{Mo}_{x} \mathrm{Nb}_{1-x}$ system is ideal for such a study since susceptibility data by Clogston et al. [199] have shown that the $\mathrm{Fe}$ atoms have a localized moment in $\mathrm{Mo}(2.2 \beta)$ but not in $\mathrm{Nb}$, the critical concentration at which the moment appears being around $x=0.4$ after what it rises continuously. Clogston et al. [178] explained this observation on the basis of a continuous change in moment per iron atom while Jaccarino and Walker [211] suggested a discontinuous magnetization process, the moment being either zero or having some maximum value. Susceptibility measurements could not help in making a choice between these two models, but such a choice could be made on the basis of HFMS experiments. According to the first interpretation, only one spectrum is expected while the resultant of two distinct spectra will be observed if the second model is correct. The subsequent experimental results [212-215] gave support to the Jaccarrino and Walker model.

6.2 KONDO EFFECT. - In some systems such as $\mathrm{CuFe}$ difficulties arose when trying to fit the field and temperature dependence of $H_{\mathrm{hf}}$ with a Brillouin function (eq. (27)). Frankel et al. [216-217] found that although the localized moments are fully polarized in the sense that decreasing $T$ does not change $H_{\mathrm{hf}}$, the magnitude of $H_{\mathrm{hf}}^{S}$ does depend upon $H_{\mathrm{ext}}$ and, as shown in figure 7 , increases with $H_{\text {ext }}$. These authors interpreted their results on the basis of a spin compensated state (Kondo effect) having a singlet nature, which forms at low temperatures. When an external magnetic field is applied, perturbation of the spin compensated state leads to a field dependent effective moment which, according to the field dependence of $H_{\mathrm{hf}}^{S}$ would be fully restored when $H_{\text {ext }}$ reaches $235 \mathrm{kOe}$. New experiments [218-219] in CuFe have confirmed these observations which have been extended by HFMS to other systems including $\mathrm{Cu}-\mathrm{NiFe}$ [203], RhFe [220-224], Rh-PdFe [222], MoFe [221, 225, 226] 


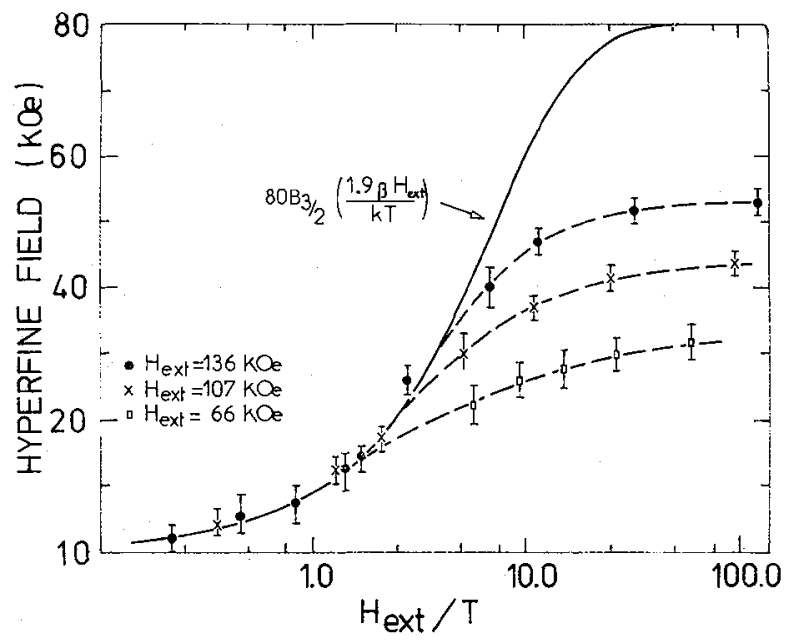

FIG. 7. $-H_{\mathrm{hf}}$ in $\mathrm{Cu}^{57} \mathrm{Co}$ plotted as a function of $H_{\mathrm{ext}} / T$ for three values of $H_{\text {ext. }}$. The solid line is a Brillouin function for $J=3 / 2$, fitted to the data at high temperatures. Note that $H_{\mathrm{h}}^{S}$ (dotted lines) depends upon $H_{\text {ext }}$ (after ref. [216]).

and very dilute PtFe at very low temperatures $(57 \mathrm{mK})$ [227]. All these systems present a characteteristic field dependent $H_{\mathrm{hf}}^{\mathrm{s}}$ and one main difficulty which arises in the interpretation is the determination of the true $H_{\mathrm{hf}}^{S}$, i. e. the one corresponding to the fully restored moment. Saturation hyperfine fields observed in several concentrated $\mathrm{CuFe}$ alloys have been extrapolated to zero iron concentration by Window [218]. He found a value $-80 \pm 3 \mathrm{kOe}$ which is exactly the value extrapolated by Frankel et al. [216] for very dilute alloys. The AuFe system is still an essentially open problem. The most recent high field Mössbauer results of Steiner et al. [132] lead to the conclusion that impurity-impurity interactions are still important even in the extremely low concentration limit (smaller than $10 \mathrm{ppm}$ ) and that it is not possible to observe Kondo phenomena because they are obscured by the interaction effects.

No localized moment has been observed in iron doped beryllium [228]. The reason could be a high Kondo temperature $(>1000 \mathrm{~K})$. Measurements in external field place also an upper limit of $0.1 \beta$ for a moment localized on $\mathrm{Np}$ in $\alpha-\mathrm{Np}$ metal [229] in agreement with band calculations for the actinide metals which show that the 5 f electrons are not localized but are hybridized into rather wide conduction bands. It is possible however, to obtain localized moments on $\mathrm{Np}$ impurities in other actinide metals such as Am or in Pd [230]. Finally it would be interesting to have an estimate of the dimension of the Kondo bound state which can be looked at as a compensation cloud of polarized conduction electrons. High field Mössbauer studies of RhFe [221] show essentially a local character of the compensation in marked contrast with the model of a large diffuse cloud [231,232], but it seems that the problem is still open. In CuFe high field and very low temperature measurements by Steiner et al. [219] indicate a small antiferromagnetic polarization of the electron gas in the Kondo state.

7. Experimental aspects. - 7.1 MAGNETS. - Experimental aspects of the Mössbauer spectroscopy have been reviewed in several articles, some of them quite recently $[233,236]$. However relatively little space has been devoted to the specific aspects of the use of magnetic fields in Mössbauer spectroscopy although one should mention the papers presented at the first Symposium on Mössbauer Effect Methodology by Blum [237] on the use of water-cooled solenoids and by Graig [238] on that of superconducting magnets. Since then, the technology of this last type of magnet has improved so rapidly that they are used in the vast majority of measurements. Among the recent developments one may quote a $128 \mathrm{kOe}, 6.5 \mathrm{~cm}$ bore $\mathrm{Nb}-\mathrm{Sn}$ magnet [239], a $60 \mathrm{kOe}$ omnidirectional magnet consisting of a pair of $\mathrm{Nb}-\mathrm{Ti}$ Helmoltz coils [240], a $3.2 \mathrm{~cm}$ bore special magnet for Mössbauer studies giving a maximum field of $115 \mathrm{kOe}$ [241]. The highest field produced to date seems to be $158 \mathrm{kOe}$ at $4.2 \mathrm{~K}$ and $165 \mathrm{kOe}$ at $3.0 \mathrm{~K}$ in a $2.6 \mathrm{~cm}$ bore $\mathrm{Nb}-\mathrm{Sn}$ magnet [241]. The main advantages of the superconducting magnets [242] are relatively low cost, small size and absence of vibration. One drawback is a rather slow field sweep rate although this fact is not of major concern for the majority of Mössbauer experiments. Depending upon the kind of experiment, liquid helium temperature may or may not be considered as a advantage. $\mathrm{Nb}-\mathrm{Zr}$ or $\mathrm{Nb}-\mathrm{Ti}$ magnets which are limited around $70 \mathrm{kOe}$ may have their maximum field substantially increased (up to $90 \mathrm{kOe}$ ) by the addition of iron or dysprosium ferromagnetic concentrators $[243,244]$ at the expense of course of the bore dimensions. Despite the wide-spread use of the superconducting coils, other types of magnets are not without attractive points. For long duration experiments which do not require a field larger than 20-25 kOe, the use of a conventional electromagnet is recommended. Recently Petitt et al. [245] modified such a magnet and reached fields in excess of $25 \mathrm{kOe}$, large enough to adequately separate the two sublattice hyperfine fields of $\mathrm{Li}-\mathrm{Zn}$ ferrite. An industrial application of the Mössbauer effect using an electromagnet has been reported [246].

On the other hand, if very high fields in the 100$200 \mathrm{kOe}$ range are needed, one must turn to water-cooled solenoids of the type designed by F. Bitter [237]. In addition to the magnitude of the field, their main advantages are the fast sweep rate (about one minute) and the convenience of a $5 \mathrm{~cm}$ bore, with adequate space for room temperature experiments (such as measuring the sign of the efg), high or low temperature equipments. They have however two important drawbacks. First, they are available only at a few major installations (about 10 in the world), secondly, they are affected by a high level of mechanical vibration resulting from the huge flow of cooling water. 
Great care has to be taken in order to avoid line broadening [237, 247]. This is generally done by a sophisticated arrangement in which a shaft is mounted on shock absorbers. At the Service National des Champs Intenses in Grenoble the best isolation has been obtained by using automobile tire inner tubes with an air pressure which is a function of the weight of the spectrometer and of the resonance frequency $[247,248]$.

7.2 MösSbauer EQUiPMENT. - Let us now look at the basic parts of an usual Mössbauer spectrometer and discuss the problems one must face because of the presence of a magnet. They essentially arise because all types of magnets produce stray fields in their neighborhood. For instance scintillation detectors are prohibited unless the photomultiplier is removed from the neighborhood of the magnet and a light pipe used to guide the light from the $\mathrm{NaI}(\mathrm{Tl})$ crystal to the photomultiplier. There is however some loss of resolution and when it is possible they are replaced by proportional or semi-conductor particle detectors [249, 250] which are quite insensitive to magnetic fields. With conventional electromagnets, Petitt et al. [245] have found it advantageous to increase the counting rate by placing the detector inside the tapered pole caps. In that case commercially available $[251,252]$ end window proportional detectors [253] are the best choice. A way of increasing the counting rate is to place both source and absorbers in the magnet. This increases the complexity of the spectra but this is generally a problem easily solved by computer techniques. This method has the additional advantage that it permits the determination of the sign of hyperfine fields [116].

In most experiments, either the source or the absorber is assumed to be in zero field, in order to have a single emission or absorption line. Fringing fields however are frequently not negligible and can induce large internal fields, specially at low temperatures. An interesting way of avoiding this effect was suggested independently by Swartzendruber [254] and Clark [255]. The argument developed by Clark is as follows : using eq. (28) the effective field at the nucleus can be expressed as:

$$
H_{\mathrm{eff}}=H_{\mathrm{hf}}+H_{\mathrm{ext}}=H_{\mathrm{ext}}\left(1+\frac{C}{T}\right)
$$

where

$$
C=H_{\mathrm{hf}}^{S} \frac{(J+1) \mu}{3 J k} .
$$

In the most commonly used Mössbauer sources (for example ${ }^{57} \mathrm{Co}$ in $\mathrm{Pd}, \mathrm{Pt}$ or $\mathrm{Cu}$ ) the induced hyperfine field is oppositely directed to the applied field, i. e. $C$ is negative. It is therefore possible to find a cancellation temperature $T_{0}$ for which $1+C / T_{0}=0$. At $T=T_{0}$ the effective field seen by the source nuclei vanishes. For a ${ }^{57} \mathrm{Co}$ in $\mathrm{Pd}$ [2] source, Clark [255] has plotted the cancellation temperature versus $H_{\text {ext }}$. For fields up to $80 \mathrm{kOe}, T_{0}=110 \pm 10 \mathrm{~K}$ and remains constant to within $5 \mathrm{~K}$. For ${ }^{57} \mathrm{Co}$ in $\mathrm{Cu}$ [216] $H_{\mathrm{hf}}$ does not follow a simple Brillouin function as discussed previously and it is not possible to predict the cancellation temperature. Also for $\mathrm{Eu}$ experiments Nowik et al. [40] took advantage of the fact that in $\mathrm{Eu}^{3+}$ the hyperfine field from $4 \mathrm{f}$ electrons induced by an external field is of opposite sign and almost equal to the external field.

Stray fields can also seriously affect the normal measurements which are made to effect a velocity calibration of the spectrometer. Since the magnetic hyperfine interaction changes with the field produced by the magnet it is advisable to provide a facility for simultaneous calibration of the velocity scale. For this purpose it suffices to have a second Mössbauer source attached to the side of the transducer opposite to the high field region. This requires either the use of two multichannel analysers or alternatively a small computer [256] or an electronic interface permitting the memory of a single multichannel analyser to be shared between the two data acquisition units [257].

In order to avoid the effect of stray fields on transducers, the source is sometimes driven by means of a long non magnetic rod (i. e. stainless steel or plastic, for example) which may be as long as one meter. Such an arrangement and the additional presence of bellows used to introduce the motion into a vacuum space results in a heavy load for the transducer and a. large driving force is needed [258]. Under such conditions a sinusoidal motion is generally more suitable than the parabolic constant acceleration mode normally employed [259]. The driving rod however may be a source of errors since it has a certain elasticity and it would be preferable to utilize a device for measuring the velocity close to the source. One possibility is to replace the velocity pick up system by an acceleration pick up system through accelerometers [260] which are commonly used for vibration measurements. It has been found that accelerometers can be controlled more easily with a sinusoidal motion than a parabolic one [261].

It is generally easy to house superconducting magnets in low temperature dewars [233-235]. In fact in those experiments when one looks for high values of $H_{\mathrm{ext}} / T$ the achievement of very low temperatures $(30$ to $100 \mathrm{mK}$ in $\mathrm{He}^{3} / \mathrm{He}^{4}$ dilution refrigerators for example [262-264]) permits the use of small magnets. On the other end of the temperature scale, putting a furnace inside a superconducting coil can be a problem. Coey et al. [265] succeeded in building such a vacuum furnace which allows one to obtain Mössbauer spectra at temperatures up to $500^{\circ} \mathrm{C}$ in external fields of up to $50 \mathrm{kOe}$.

Temperature control in the presence of high field magnets is a major problem in the sense that the great majority of the temperature sensors are field sensitive. 
Moreover the effect of the field is not always reproducible with the commonly available sensors and varies from one production run of sensors to another. The magneto-resistance is also often anisotropic. Therefore care has to be taken with the precise orientation of the temperature sensor with respect to the magnetic field. The magnetic field behavior of several low temperature thermometers has been extensively studied by Neuringer and Rubin [267]. Their measurements include carbon, germanium and platinum resistance thermometers, thermistors, GaAs diodes, thermocouples and $\mathrm{SrTiO}_{3}$ glass ceramic capacitors in fields of up to $150 \mathrm{kOe}$. This last sensor seems to be particularly promising because it is almost insensitive to the field : up to $150 \mathrm{kOe}$ in the interval 1.5 to $4.2 \mathrm{~K}$, the maximum apparent temperature shift developped by the sensor is less than $1 \mathrm{mK}$; between 4.2 and $20 \mathrm{~K}$ the shift is less than $5 \mathrm{mK}$ and it is likely that this favorable situation holds for temperatures up to $60 \mathrm{~K}$.

Conversely calibration of the external field can be made using the above field sensitive sensors. However for most Mössbauer experiments a common way of calibrating is to use a diamagnet such as sodium ferrocyanide, the measured effective field being equal to the applied field. Swartzendruber and Bennett [267] have proposed to use $\mathrm{TiFe}$ as a calibration material because knight shifts of ${ }^{57} \mathrm{Fe}$ in $\mathrm{TiFe}$ are accurately known [268].

Acknowledgments. - Stimulating discussions with M. Belakhovsky, C. Benski, J. M. D. Coey and R. H. Herber are gratefully acknowledged.
[1] Hanna, S. S., Heberle, J., Perlow, G. J., Preston, R. S. and Vincent, D. H., Phys. Rev. Lett. 4 (1960) 513.

[2] Craig, P. P., Nagle, D. E., Steyert, W. A. and Taylor, R. D., Phys. Rev. Lett. 9 (1962) 12.

[3] Blum, N. A., Freeman, A. J. and Grodzins, L., Rev. Mod. Phys. 36 (1964) 406.

[4] Buum, N. A., Thesis, National Magnet Laboratory, Report NML 64-2 (1964).

[5] Heberle, J., in Mössbauer Effect Methodology ed. by Gruverman, I. J. (Plenum Press, New York) Vol. 2 (1966) p. 95.

[6] Abragam, A. and Pryce, M. H. L., Proc. R. Soc. A 205 (1951) 135.

[7] For a review see Abragam, A. and Bleaney, B., Electron Paramagnetic Resonance of Transition Ions (Oxford Univ. Press) 1969.

[8] Johnson, C. E., Proc. Phys. Soc. 92 (1967) 748.

[9] Marshall, W. and Johnson, C. E., J. Physique Radium 23 (1962) 733

[10] JoHnson, C. E., in Hyperfine Structure and Nuclear Radiations ed. by Matthias, E. and Shirley, D. A. (North Holland, Amsterdam) 1968, p. 226.

[11] JoHnson, C. E., in Hyperfine Interactions in Excited Nuclei, Vol. 3, ed. by Goldring G. and Kalish R. (Gordon and Breach New York) 1971, p. 803.

[12] Lang, G. and Marshall, W., Proc. Phys. Soc. 87 (1966) 3.

[13] LANG, G. and Dale, B. W., J. Phys. C 6 (1973) L 80.

[14] Vaughan, D. J. and Ridout, M. S., J. Inor. Nucl. Chem. 33 (1971) 741

[15] LANG, G., in Mössbauer Spectroscopy and its Applications, Proceedings of a panel, I. A. E. A., Vienne (1972) p. 213.

[16] Johnson, C. E., Nature 217 (1968) 446.

[17] Winter, M. R. C., Johnson, C. E., LANG, G. and WILLIAMS, R. J. P., Bioch. Biophys. Acta 263 (1972) 515.

[18] Chappert, J., Frankel, R. B., Misetich, A. A. and Blum, N. A., Phys. Rev. 179 (1969) 578.

[19] Chappert, J., Misetich, A., Frankel, R. B. and Blum, N. A., Phys. Rev. B 1 (1970) 1929.

[20] Chappert, J., Frankel, R. B. and Blum, N. A., Phys. Lett. 25A (1967) 149.

[21] Regnard, J. R., Chappert, J. and Ribeyron, A., Solid State Commun. to be published.

[22] Frankel, R. B., Chappert, J., Regnard, J. R., MiseTICH, A. A. and Abeledo, C. R., Phys. Rev. B 5 (1972) 2469.
[23] Oosterhuis, W. T. and Lang, G., Phys. Rev. 178 (1969) 439.

[24] Oosterhuis, W. T., Weaver, D. L. and Paez, E. A., $J$. Chem. Phys. 60 (1974) 1018.

[25] Parker, F. T. and Kaplan, M., Phys. Rev. B 8 (1973) 4318.

[26] Freeman, A. J. and Watson, R. E., in Magnetism $2 A$, ed. by Rado, G. T. and Suhl, H. (Acad. Press, New York) 1965 p. 167.

[27] For a review see HAM, F. S., in Electron Paramagnetic Resonance, ed. by Geschwind, S. (Plenum Press, New York) 1972, p. 1.

[28] Geschwind, S., in Hyperfine Interactions, ed. by Freeman, A. J. and Frankel, R. B. (Acad. Press, New York) 1967, p. 225

[29] Parker, F. T. and Kaplan, M., J. Chem. Phys. 60 (1974) 1328.

[30] Watson, R. E. and Freeman, A. J., in Hyperfine Interactions, ed. by Freeman, A. J. and Frankel, R. B. (Acad. Press, New York) 1967, p. 53.

[31] Wertheim, G. K. and Remeika, J. P., Phys. Lett. 10 (1964) 14.

[32] König, E., Ritter, G. and Zimmermann, R., Chem. Phys. Lett. 26 (1974) 425.

[33] Rao, K. K., Evans, M. C. W., Cammack, R., Hall, D. O., Thompson, C. L., JACKsON, P. J. and Johnson, C. E., Biochem. J. 129 (1972) 1063.

[34] Spiering, H., Zimmermann, R. and Ritter, G., Phys. Stat. Sol. b 62 (1974) 123.

[35] Sands, R. H., Phys. Rev. 99 (1955) 1222.

[36] Johnson, C. E., Rickards, R. and Hill, H. A. O., J. Chem. Phys. 50 (1969) 2594.

[37] König, G., RitTer, G., Lindner, E. and-Lorenz, I. P., Chem. Phys. Lett. 13 (1972) 70.

[38] Stampfel, J. P., Oosterhuis, W. T., Window, B., de S. Barros, F., Phys. Rev. B 8 (1973) 4371.

[39] Nowik, I., Dúnlap, B. D., Kalvius, G. M., Phys, Rev. B 6 (1972) 1048

[40] Nowik, I., DunlaP, B. D. and Wernick, J. H., Phys. Rev. B 8 (1973) 238.

[41] Lang, G., Asakura, T. and Yonetani, T., J. Phys. C 2 (1969) 2246.

[42] Zimmermann, R., Spiering, H. and Ritter, G., Chem. Phys. 4 (1974) 133.

[43] Vicarro, P. J., de S. Barros, F. and Oosterhuis, W. T., Phys. Rev. B 5 (1972) 4257. 
[44] Fitzsimmons, B. W. and Johnson, C. E., Chem. Phys. Lett. 24 (1974) 422.

[45] Oosterhuis, W. T. and Spartalian, K., $J$, Physique Collq. 35 (1974) C6-347.

[46] Johnson, C. E., Phys. Lett. 21 (1966) 491.

[47] LANG, G., Quart. Rev. Biophysics 3 (1970) 1.

[48] Suzdalev, I. P., Korneev, V. P. and Krupiansky, Yu. F., in Proceedings of the Conference on the Application of the Mössbauer Effect, ed. by Deszi, I. (Akademiai Kiado, Budapest) 1971, p. 147.

[49] PaEz, E. A., Weaver, D. L. and Oosterhuis, W. T., $J$. Chem. Phys. 57 (1972) 3709.

[50] Oosterhuis, W. T. and de S. Barros, F., J. Chem. Phys. 57 (1972) 4304

[51] Oosterhuis, W. T. and LANG, G., J. Chem. Phys. 58 (1973) 4757.

[52] Wickman, H. H. and Wertherm, G. K., Phys. Rev. 148 (1966) 211.

[53] Ruby, S. L. and Flinn, P. A., Rev. Mod. Phys. 36 (1964) 351.

[54] Coluins, R. L., J. Chem. Phys. 42 (1965) 1072.

[55] Collins, R. L. and Travis, J. C., in Mössbauer Effect Methodology, ed. by Gruverman, I. J. (Plenum Press, New York) Vol. 3 (1967) p. 123.

[56] Dale, B. W., Williams, R. J. P., Edwards, P. R. and Johnson, C. E., J. Chem. Phys. 49 (1968) 3445.

[57] Coey, J. M. D., Dezsi, I., Thomas, P. M. and OUSePh, P. J., Phys. Lett. 41A (1972) 125.

[58] Ablov, A. V., Gerbeleu, N. V., GoldanskiI, V. I., StUKAN, R. A. and TURTA, K. I., Russ. J. Inorg. Chem. 16 (1971) 96 ;

Camprell, M. J. M., Chem. Phys. Lett. 15 (1972) 53.

[59] Reiff, W. M., Inorg. Chem. 13 (1974) 239.

[60] Grant, R. W., Wiedersich, H., Muir, A. H., Gonser, U. and Delgass, W. N., J. Chem. Phys. 45 (1966) 1015.

[61] Goodman, B. A. and Greenwood, N. N., Chem. Comm. (1969) 1105

[62] Gibs, T. C., J. Chem. Soc. A (1970) 2503.

[63] LANG, G., J. Chem. Soc. A (1971) 3245.

[64] Travis, J. C. and Coluins, R. L., in Proc. Second Symp. Low Energy $X$ - and Gamma Sources, ORNL Rep. No. IIC-10, Austin, Tex., USA (1967).

[65] Reuff, W. M., Coordin. Chem. Reviews 10 (1973) 37.

[66] GibB, T. C., Goodman, B. A. and Greenwood, N. N., Chem. Comm. (1970) 774 ;

Evans, B. J., Hafner, S. S, and Weber, H. P., J. Chem. Phys. 55 (1971) 5282.

[67] ReifF, W. M., J. Amer. Chem. Soe. 95 (1973) 3048.

[68] ReIfF, W; M., ERICKSON, N. E. and BAKER, W. A., Inorg. Chem. 8 (1969) 2019.

[69] Merrell, D. H., Goedken, V. L., Busch, D. H. and STONE, J. A., J. Amer, Chem. Soc. 92 (1970) 7590.

[70] Reiff, W. M., J. Amer. Chem. Soc. 96 (1974) 3829.

[71] Edwards, P. R., Johnson, C. E. and Williams, R. J. P., J. Chem. Phys. 47 (1967) 2074.

[72] KöniG, E., Ritter, G., LindneR, E. and LoRenz, I. P., Chem. Phys. Lett. 13 (1972) 70.

[73] Sams, J. R. and Tsin, T. B., Chem. Phys. Lett. 25 (1974) 599.

[74] Dezsi, I. and KeszTHelYi, L., Solid State Commun. 4 (1966) 511 .

[75] Reiff, W. M., Frankel, R. B. and Abeledo, C. R., Chem. Phys. Lett. 22 (1973) 124.

[76] Latorre, R., Abeledo, C. R., Frankel, R. B., CostaMagna, J. A., ReIFF, W. M. and Frank, E., J. Chem. Phys, 59 (1973) 2580.

[77] ReIFF, W. M., J. Chem. Phys. 54 (1971) 4718.

[78] Uhrich, D. L., Stroh, J., D'SidockY, R. and Fishel, D. L., Chem. Phys. Lett. 24 (1974) 539 and references therein.

[79] MarshalL, W., in Proceedings of the Second International Conference on the Mössbauer Effect, ed. by Compton, D. M. J. and Schoen, A. H. (Wiley, New York) 1961, p. 141.

[80] HaM, F. S., Phys. Rev. 160 (1967) 328.
[81] Ganiel, U. and Shtrikman, S., Phys. Rev. 167 (1968) 514. [82] Hoy, G. R. and Singh, K. P., Phys. Rev. 172 (1968) 514.

[83] Kamal, R. and Mendiratta, R. G., Phys. Rev. B 3 (1971) 1649.

[84] LeIDer, H. R. and PIPKORn, D. N., Phys. Rev. 165 (1968) 494.

[85] Regnard, J. R., J. Physique Collq. 35 (1974) C6-181.

[86] Ham, F., Schwarz, W. M. and O'Brien, M. C. M., Phys. Rev. 185 (1969) 548.

[87] Chappert, J., Frankel, R. B., Misetich, A. and Blum, N. A., Phys. Lett. 28 B (1969) 406.

[88] Ginsberg, A. P., Martin, R. L. and Sherwood, R. C., Chem. Comm. (1967) 856 .

[89] Martin, R. L., in New Pathways in Inorganic Chemistry, ed. by Ebsworth, E. A. V., Maddock, A. G. and Sharpe, A. G. (Univ. Press., Cambridge, England) 1968, p. 175.

[90] Sinn, E., Coordin. Chem. Rev. 5 (1970) 313.

[91] Kambe, K., J. Phys. Soc. Japan 5 (1950) 48.

[92] Lechan, R., Nicolini, C., Abeledo, C. R. and Frankel, R. B., J. Chem. Phys. 59 (1973) 3138.

[93] Okamura, M. Y., Klotz, I. M., Johnson, C. E., WinTER, M. R. C. and WILliams, R. J. P., Biochemistry 8 (1969) 1951.

[94] BuCKley, A. N., HerberT, I. R., Rumbold, B. D., WiLson, G. V. H. and Murray, K. S., J. Phys. Chem. Solids 31 (1970) 1423.

[95] Reiff, W. M., J. Chem. Phys. 54 (1971) 4718.

[96] ReIFF, W. M., in Mössbauer Effect Methodology, ed. by Gruverman, I. J. (Plenum Press, New York) 1971 Vol. 7, p. 213.

[97] Mayerle, J. J., Frankel, R. B., Holm, R. H., Ibers, J. A., Phillips, W. D. and Weiher, J. F., Proc. Nat: Acad. Sci. USA 70 (1973) 2429.

[98] BuCKLEY, A. N., RuMbold, B. D., Wilson, G. V. H., Murray, R. S., J. Chem. Soc. A (1970) 2298.

[99] Dalziel, J. A. W., Donaldson, J. D., Memta, B. D. and TriCKer, M. J., J. Inorg. Nucl. Chem. 35 (1973) 3811.

[100] Fitzsimmons, B. W. and Johnson, C. E., Chem. Phys. Lett. $6(1970) 267$.

[101] Murray, K. S., Coordin. Chem. Reviews 12 (1974) 1.

[102] Takano, M., J. Phys. Soc. Japan 33 (1972) 1312.

[103] Rumbold, B. D., Wilson, G. V. H., J. Phys. Chem. Solids 34 (1973) 1887.

[104] Frankel, R. B., Reiff, W. M., Bernal, I., Good, M. L., Inorg. Chem. 13 (1974) 493.

[105] Frauenfelder, H., Gunsalus, I. C. and Münck, E., in Mössbauer Spectroscopy and its Applications, Proceedings of a panel, I. A. E. A., Vienne (1972) p. 231.

[106] Johnson, C. E., J. Physique 35 (1974) C1-57.

[107] Frankel, R. B., J. Physique Collq. 35 (1974) C6-107.

[108] Parak, F., Bogner, L., Eicher, H., Kalvius, G. M., Gersonde, K. and SchlaAk, H. E., J. Physique Collq. 35 (1974) C6-367.

[109] Dickson, D. P. E., Johnson, C. E., Thompson, C. L., Cammack, R., Evans, M. C. W., Hall, D. O., Rao, K. K. and WeSER, U., J. Physique Collq. 35 (1974) C6-343.

[110] Pauthenet, R., Ann. Phys. 5 (1970) 51.

[111] Cinader, G. and Shtrikman, S., Solid State Commun. 4 (1966) 459.

[112] Beckmann, V., Bruckner, W., Fuchs, W., Ritter, G. and WEGENER, H., Phys. Stat. Sol. 29 (1968) 781.

[113] Beckmann, V., Ritter, G., Spiering, H. and Wegener, H., Proceedings of the Conference on the Application of the Mössbauer Effect, ed. by Deszi, I. (Akademiai Kiado, Budapest) 1971, p. 147.

[114] OK, H. N., Helms, W. R. and Mullen, J. G., Phys. Rev. 187 (1969) 704.

[115] Fletcher, E. J. and O'Reilly, W., J. Phys. C 7 (1974) 171.

[116] Blum, N. A. and Grodzins, L., Phys. Rev. 136 (1964) A 133 .

[117] Rickards, R., Johnson, C. E. and Hill, H. A. O., Trans. Faraday Soc. 65 (1969) 2847. 
[118] Longworth, G., J, Phys. C : Metal Phys. Suppl. 3 (1970) S 81.

[119] Frankel, R. B., in Mössbauer Effect Methodology, ed. by Gruverman, I. J. (Plenum Press, New York) Vol. 9 (1974).

[120] Shapira, Y. and Foner, S., Phys. Rev. B 1 (1970) 3083.

[121] Blum, N., Freeman, A. J., Shaner, J. W. and Grodzins, L., J. Appl. Phys. 36 (1965) 1169.

[122] Simkin, D. J. and Bernheim, R. A., Phys. Rev. 153 (1967) 621.

[123] Simkin, D. J., Phys. Rev. 177 (1969) 1008

[124] Forester, D. W. and Koon, N. C., J. Appl. Phys. 40 (1969) 1316.

[125] Edwards, P. R. and Johnson, C. E., J. Chem. Phys. 49 (1968) 211.

[126] Wertheim, G. K., Buchanan, D. N. E., Wernick, J. H., Solid State Commun. 8 (1970) 2173.

[127] Abeledo, C. R., Frankel, R. B., Misetich, A., Blum, N. A., J. Appl. Phys. 42 (1971) 1723.

[128] Carroll, T. X. and Kaplan, M., Chem. Phys, Lett. 22 (1973) 564.

[129] Stampfel, J. P., Oosterhuis, W. T., Window, B. and de S. Barros, F., Phys, Rev. B 8 (1973) 4371.

[130] Kandel, L., Weber, M. A., Frankel, R. B. and AbeLEDo, C. R., Phys. Lett. 46A (1974) 369

[131] Imbert, P., MACheteau, Y. and VARret, F., J. Physique 34 (1973) 49.

[132] Steiner, P., Beloserskij, G. N., Gumprecht, D., ZdroJEWSKI, W. V. and HüFner, S., Solid State Commun. 14 (1974) 157 and references therein.

[133] Johnson, C. E., J. Phys. C 2 (1969) 1996.

[134] Takano, M., Shinjo, T., Kiyama, M. and Takada, T., $J$. Phys. Soc. Japan 35 (1973) 53.

[135] Iтo, A. and Ono, K., J. Phys. Soc. Japan 26 (1969) 1548.

[136] Hartford, R. H. and CASPARI, M. E., Mat. Res. Bull. 6 (1971) 989.

[137] Longworth, G. and Harris, I. R., J. Less Commun. Metals 33 (1973) 83.

[138] Craig, P. P. and SteYert, W. A., Phys. Rev. Leit. 13 (1964) 802.

[139] Chappert, J. and Frankel, R. B., Phys. Rev. Lett. 19 (1967) 570.

[140] Baltzer, P. K. and Wojtowicz, P. J., J. Appl. Phys. 30 (1959) $27 \mathrm{~S}$.

[141] JACOBS, I. S., J. Phys. Chem. Solids 15 (1959) 54.

[142] For a review see Rosencwaig, A., Can. J. Phys. 48 (1970) 2857 and references therein.

[143] Yafet, Y. and Kittel, C., Phys.' Rev. 87 (1952) 290

[144] Clark, P. E. and Morrish, A. H., Phys. Stat. Sol. a 19 (1973) 687.

[145] Leung, L. K., Evans, B. J. and Morrish, A. H., Phys. Rev. B 8 (1973) 29.

[146] Petrtt, G. A., Solid State Commun. 13 (1973) 1611.

[147] Daniels, J. M. and Rosencwatg, A., Can.J. Phys. 48 (1970) 381.

[148] PettTt, G. A. and Forester, D. W., Phys. Rev. B 4 (1971) 3912

[149] Frankel, R. B., Bium, N. A., Foner, S., Freeman, A. J. and Schimber, M., Phys. Rev. Lett. 15 (1965) 958.

[150] SChieber, M., Frankel, R. B., BLum, N. A. and Foner, S., J. Appl. Phys. 38 (1967) 1282.

[151] Zinn, W., HüFner, S., Kalvius, M., Kienle, P. and Wiedeman, W., Z. Angew. Phys. 17 (1964) 147.

[152] RitTer, G., Z.Phys. 189 (1966) 23.

[153] Sawatzky, G. A., van DeR Woude, F. and Morrish, A. H., Phys. Lett. 25A (1967) 147.

[154] Sawatzky, G. A., van Der Woude, F. and Morrish, A. H., Phys. Rev. 187 (1969) 747.

[155] Dmitrieva, T. V., Lyubutin, I. S., PokrovskiI, B. I. and Bondareva, N. D., Sov. Phys. JETP 36 (1973) 709.

[156] Lyubutin, I. S., DMitrieya, T. V. and Belyaev, L. M., Sov. Phys. Solid State 14 (1973) 2579.
[157] Evans, B. J. and Hafner, S. S., J. Phys. Chem. Solids 29 (1968) 1573

[158] Sawatzky, G. A., van Der Woude, F., Morrish, A. H., J. Appl. Phys. 39 (1968) 1204.

[159] Spender, M. R., Coey, J. M. D. and Morrish, A. H., Can. J. Phys. 50 (1972) 2313

[160] Evans, B. J. and Hafner, S. S., J. Appl. Phys. 40 (1969) 1411.

[161] Daniels, J. M. and Rosencwaig, A., J. Phys. Chem. Solids 30 (1969) 1561.

[162] Hargrove, R. S. and KüNDIG, W., Solid State Commun. 8 (1970) 303.

[163] Rubinstein, M. and Forester, D. W., Solid State Commun. 9 (1971) 1675.

[164] Coey, J. M. D., Morrish, A. H. and Sawatzky, G. A., J. Physique 32 (1971) C 1-271.

[165] Coey, J. M. D., Phys. Rev. B 6 (1972) 3240.

[166] SaWatzky, G. A., Vander Woude, F. and Morrish, A. H., Phys. Rev. 183 (1969) 383.

[167] Trooster, J. M. and Dynamus, A., Phys. State Solid 24 (1967) 487.

[168] Belakhovsky, M., Chappert, J., Rouskov, T. and SivarDIÈre, J., J. Physique 32 (1971) C 1-492.

[169] Exbschïtz, M. and Shrrikman, S., J. Appl. Physics 39 (1968) 997.

[170] Linguist, R. H., Constabaris, G., Kündig, W. and Portis, A. M., J. Appl. Phys. 39 (1968) 1001.

[171] VAN DER KraAN, A. M., $J$. Physiquie 32 (1971) C1-1035.

[172] Ohya, T. and Ono, K., J. Chem. Phys. 57 (1972) 3240.

[173] Roggwiller, P. and Kundig, W., Solid State Commun. 12 (1973) 901

[174] Coey, J. M. D., Phys. Rev. Lett. 27 (1971) 1140.

[175] Coey, J. M. D. and Khalafalla, D., Phys. Stat. Sol. 11 (1972) 229.

[176] Bukrey, R. R., Kenealy, P. F., Beard, G. B. and HooPER, H. O., Phys. Rev. B 9 (1974) 1052.

[177] CoEY, J. M. D. and Readman, P. W., Nature 246 (1973) 476.

[178] Coey, J. M. D., J. Physique Collq. 35 (1974) C6-89.

[179] Craig, P. P., Perisho, R. C., Segnan, R. and Steyert, W. A., Phys. Rev. 138 (1965) A 1460.

[180] Freeman, A. J., Blum, N. A., Foner, S., Frankel, R. B. and McNufF Jr, E. J., J. Appl. Physics 37 (1966) 1338.

[181] Frankel, R. B., Phys. Lett. 30A (1969) 269.

[182] Tansil, J. E., Obenshain, F. E. and CzIzeK, G., Phys. Rev. B 6 (1972) 2796

[183] Wertheim, G. K. and Wernick, J. H., Acta. Met. 15 (1967) 297.

[184] Frankel, R. B., Sellmeyer, D. J. and Blum, N. A., Phys. Lett. 33A (1970) 13

[185] Wertheim, G. K., Wernick, J. H. and Buchanan, D. N. E., J. Appl. Phys. 37 (1966) 3333.

[186] Maletta, H., Frankel, R. B., Henning, W. and MössBauer, R. L., Phys. Lett. 28A (1969) 557.

[187] Window, B., Phil. Mag. 26 (1972) 681; CAMPBell, S. J. and Clark, P. E., J. Phys. F 4 (1974) 1073.

[188] Swartzendruber, L. J. and Bennett, L. H., Phys. Lett. 27A (1968) 141.

[189] Window, B. and Johnson, C. E., Phys. Lett. 29A (1969) 703 .

[190] Bennett, L. H. and Swartzendruber, L. J., Acta Met. 18 (1970) 485.

[191] Makarov, V. A., Granovskit, E. B., Makarov, E. F. and Povitskir, V. A., Phys. Stat. Sol. a 14 (1972) 331.

[192] Nasu, S., Gonser, U., Shingu, P. H. and Murakani, Y. J. Phys. F 4 (1974) L 24

[193] Alloul, H. and Bernier, P., Annis. Phys. 8 (1974) 169.

[194] Rizzuto, C., Rept. Progr. Phys. 37 (1974) 147.

[195] SChWartz, B. B. and Frankel, R. B., in Mössbauer Effect Methodology, ed. by Gruverman, I. J., Vol. 7 (1971) p. 21. 
[196] Kitchens, T. A. and TAYloR, R. D., Phys. Rev. B 9 (1974) 344.

[197] Flouquet, J., Annls. Phys. 8 (1974) 5.

[198] Flouquet, J. and Brewer, W. D., Intern. Conf. on Hyperfine Interactions studied in nuclear reactions and decay, Uppsala (1974).

[199] Clogston, A. M., Matthias, B. T., Peter, M., Williams, H. J., CoRenzwit, E. and Sherwood, R. C., Phys. Rev. 125 (1962) 541

[200] Kitchens, T. A., Steyert, W. A. and Taylor, R. D., Phys. Rev. 138 (1965) A 467.

[201] Freeman, A. J., Phys. Rev. 130 (1963) 888.

[202] Maley, M. P., TayloR, R. D. and Thompson, J. L., $J$. Appl. Phys. 38 (1967) 1249.

[203] Bennett, L. H., SWARTZENDRUber, L. J. and Watson, R. E., Phys: Rev. Lett. 23 (1969) 1171.

[204] Maletta, H. and Mössbauer, R. L., Solid State Commun. 8 (1970) 143

[205] Maletta, H., Z. Phys. 250 (1972) 68.

[206] Liddell, P. R. and Street, R., J. Phys. F 3 (1973) 1648.

[207] TAYLoR, R. D. and STEYert, W. A., J. Appl. Phys. 37 (1966) 1336

[208] Herbert, I. R., Clark, P. E. and Wrlson, G. V. H., $J$. Phys. Chem. Solids 33 (1972) 979.

[209] Frankel, R. B. and Blum, N. A., J. Phys. Chem. Solids 34 (1973) 1565.

[210] HousLey, R. M. and Dash, J. G., Phys. Lett. 10 (1964) 270.

[211] Jaccarino, V. and Walker, L. R., Phys. Rev. Lett. 15 (1965) 258.

[212] NagasaWa, H. and SaKai, N., J. Phys. Soc. Japan 27 (1969) 1150.

[213] Blum, N. A., Frankel, R. B. and Guertin, R. P., Bull. Am. Phys. Soc. 15 (1970) 262.

[214] Swartzendruber, L. J., Int. J. Magnetism 2 (1972) 129.

[215] MaletTA, H. and RAO, K. R. P., Int. J. Magnetism 3 (1973) 5.

[216] Frankel, R. B., Blum, N. A., Schwartz, B. B. and KIM, D. J., Phys. Rev. Lett. 18 (1967) 1051.

[217] Schwartz, B. B., Kim, D. J., Frankel, R. B. and Blum, N. A., J. Appl. Phys. 39 (1968) 698.

[218] Winoow, B., J. Phys. C : Metal Phys., Suppl. no 3 (1970) S 323 .

[219] Steiner, P., Zdrojewskx, W., Gumprecht, D. and HÜFnER, S., Phys. Rev. Lett. 31 (1973) 355.

[220] Blum, N. A., Chappert, J., Frankel, R. B. and Schwartz, B. B., Bull. Am. Phys. Soc, 13 (1968) 410.

[221] Window, B., Longworth, G. and Johnson, C. E., J. Phys. C 3 (1970) 2156

[222] Clark, P. E., J. Phys. C: Metal Phys. Suppl., n ${ }^{\circ} 2$ (1970) S 201 .

[223] Window, B., Longworth, G., Johnson, C. E., J. Physique 32 (1971) C 1-863.

[224] Clark, P. E. and Herbert, I. R., Solid State Commun. 12 (1973) 469

[225] Maley, M. P. and Taylor, R. D., Phys. Rev. B 1 (1970) 4213 .

[226] Maletta, H., Rao, K. R. P. M. and Nowik, I., Z. Phys. 249 (1972) 189.

[227] Scherg, M., Seidel, E. R., Gierisch, W., Litterst, F. J. and Kalvius, G. M., J. Physique Collq. 35 (1974) C6527.

[228] Campbell, I., Ferry, B., Impert, P. and Varret, F., C. R. Hebd. Séan. Acad. Sci Paris 271 (1970) serie B, 749.

[229] DunlaP, B. D. and Kalvius, G. M., Intern. J. Magnetism 2 (1972) 231 .

[230] Kalvius, G. M., in Mössbauer Spectroscopy and its Applications, Proceedings of a panel, Vienna, I. A. E. A (1972) p. 169.

[231] Daybell, M. D. and Steyert, W. A., Rev. Mod. Phys. 40 (1968) 380.

[232] Heeger, A. J., in Solid State Physics, ed. by Seitz, F. and Turnbull, D. (Acad. Press) Vol. 23 (1969) p. 283.

[233] Heriber, R. H. and Hazony, Y., in Physical Methods of Chemistry, ed. by Weissberger, A. and Rossiter B. (Wiley, New York) (1972) p. 215.
[234] Kalvius, G. M, and Kankeleit, E., in Mössbauer Spectroscopy and its Applications, Proceedings of a panel Vienna, I. A. E. A. (1972) p. 9.

[235] Cohen, R. L. and Wertheim, G. K., in Methods of Experimental Physics, Vol. 11, ed. by Coleman, R. V. (Acad. Press, New York) (1974) p. 307.

[236] Cranshaw, T. E., J. Phys. E 7 (1974) 497.

[237] Bưm, N. A., in Mössbauer Effect Methodology, ed. by Gruverman, I. J. (Plenum Press, New York) Vol. 1 (1965) p. 147.

[238] Craig, P. P., in Mössbauer Effect Methodology ed. by Gruverman, I. J. (Plenum Press, New York) Vol. 1 (1965) p. 135 .

[239] Stevenson, R., Cryogenics 14 (1974) 329.

[240] WAGNer, D. K., Rev. Sci. Instrum. 45 (1974) 621.

[241] FieTz, W. A. and Rosner, C. H., IEEE Trans. Mag. Vol. Mag 10 (1974) 239.

[242] For a review of the current state of the art, see Graham Jr, C. D., in Methods of Experimental Physics ed. by Coleman, R. V. (Acad. Press, New York) Vol. 11 (1974) p. 595 ;

BrechNa, H., in Superconducting Machines and Devices ed. by Foner, S. and Schwartz, B. B. (Plenum, New York) (1974) p. 139.

[243] Goncharov, I. N., Pribory $i$ Tekhnika Eksperimenta 2 (1967) 236.

[244] Goridov, S. I., Lazareva, L. S. and Morgun, V. N., Cryogenics 13 (1973) 55.

[245] Petirt, G. A. and Walter, R. J., Rev. Sci. Instrum. 44 (1973) 1635 .

[246] Tomov, T., Ruskov, T and Georgiev, S. A., in Proceedings of the Conference on the Applications of the Mössbauer Effect, ed. by Deszi, I., Academiai Kiado, Budapest (1971) p. 793.

[247] Chappert, J. and Regnard, J. R., International Colloquium Physics in High Magnetic Fields, Grenoble (1974).

[248] BeYsens, D., Revue Phys. Appl. 8 (1973) 175.

[249] Muggleton, A. H. F., J. Phys. E 5 (1972) 390.

[250] Bertolini, G., Cappellant, F. and Restelli, G., Nucl. Instrum. Meth. 112 (1973) 219.

[251] Reuter Stokes Inc., Cleveland, Ohio 44128, USA.

[252] J. and P. Engineering Ltd Reading, Berks, England.

[253] Cairns, J. A., Desborough, C. L. and Holloway, D. F., Nucl. Instrum. Meth. 88 (1970) 239.

[254] SwartZendruber, L. J., Nucl. Instrum. Meth. 69 (1969) 101.

[255] Clark, P. E., J. Phys. D 3 (1970) 337.

[256] Biran, A., Shoshani, A. and Montano, P. A., Nucl. Instrum. Meth. 89 (1970) 21

[257] Kaindl, G., Maier, M. R., Schaller, H. and WAGNeR, F., Nucl. Instrum. Meth. 66 (1968) 277.

[258] Katano, R., Nucl. Instrum. Meth. 83 (1970) 187.

[259] Halder, N. and Kalvius, G. M., Nucl. Instrum. Meth. 108 (1973) 161

[260] JACQUARD, P., Projet de $3^{e}$ année, Institut National Polytechnique de Grenoble, Grenoble (1969-70).

[261] Wappling, R. and Pernestal, K., Nucl. Instrum. Meth. 109 (1973) 1 .

[262] Ehnolm, G. I., Katila, T. E., LounasmaA, O. V. and ReIvari, P., Cryogenics 8 (1968) 135.

[263] Kalvius, G. M., Katila, T. E. and LounasmaA, O. V., in Mössbauer Effect Methodology, ed. by Gruverman, I. J. (Plenum Press, New York) Vol. 5 (1969) p. 231.

[264] OKada, K. and ShinJo, T., J. Appl. Phys. Japan 12 (1973) 1281.

[265] Cofy, J. M. D. Price, D. C. and Morrish, A. H., Rev. Sci. Instrum. 43 (1972) 54

[266] NeUringer, L. J. and Rubin, L. G., in Temperature, Its Measurement and Control in Science and Industry, Vol. 4 (1972) p. 1085 and references therein.

[267] Swartzendruber, L. J. and BenNetT, L. H., J. Res. Nat Bur. Standards 74A (1970) 691

[268] Swartz, J. C., Swartzendruber, L. J., Bennetr, L. H. and WAtson, R. E., Phys. Rev. B 1 (1970) 146 